\title{
水肥“三匀”技术对水稻水、氮利用效率的影响
}

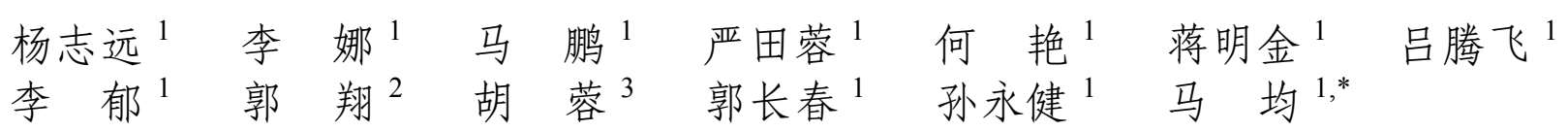

1 四川农业大学水稻研究所 / 作物生理生态及栽培四川省重点实验室, 四川成都 $611130 ;{ }^{2}$ 四川省农业气象中心, 四川成都 $610072 ;$ 3 四川省原良种试验站, 四川成都 610210

摘 要: 本研究通过 3 个裂区试验探究水肥“三匀”技术对水稻水、氮利用效率的影响。试验 1 和试验 2 土壤基础肥 力不同, 处理一致, 主区为氮高效品种德香 4103 和氮低效品种宜香 3724, 副区为农民习惯施肥模式(farmer's usual management, FU)、水肥耦合模式(nitrogen-water coupling management, NWC)、水肥“三匀”模式(methodical nitrogenwater distribution management, MNWD, 采用灌溉水和氮肥投入增频减量一体化的方式), 以各自不施氮肥为对照; 试 验 3 主区为氮高效品种德香 4103、F 优 498 及氮低效品种宜香 3724 、川优 6203 , 副区为 FU、NWC 及 MNWD。结 果表明, MNWD 施氮量较 NMC 和 FU 降低 $20 \%$, 灌溉水较 NMC 减少 $20 \%$ 25\%, 较 FU 减少 $42 \%$ 28\%。 MNWD 茎 櫱缓升缓降, 成穗率较高, 与 NWC 和 FU 相比, 其花前物质转运量较低, 但花后光合产物积累多, 与 NWC 产量差异 不显著, 较 FU 平均增产 $8.77 \% \sim 14.18 \%$ 。相关分析显示, $10 \sim 20 \mathrm{~cm}$ 及 $20 \sim 30 \mathrm{~cm}$ 土层稻株根干重与氮肥回收率、氮肥 农学利用率、灌溉水生产效率及水分生产效率显著正相关, MNWD 水稻根量大, 分布于 $10 \mathrm{~cm}$ 以下土层的根系发达, 利于水氮利用效率提高。与 NWC 和 FU 相比, MNWD 氮肥回收率平均提高 $8.07 \% \sim 11.99 \%$ 和 $20.72 \% \sim 30.78 \%$, 农学 利用率平均提高 $17.44 \% \sim 27.38 \%$ 和 $96.47 \% \sim 101.42 \%$, 灌溉水生产效率平均提高 $23.34 \% \sim 36.67 \%$ 和 $76.54 \% \sim 117.38 \%$, 水分生产效率平均提高 $8.41 \% \sim 17.66 \%$ 和 $32.23 \% \sim 65.29 \%$ 。

关键词：水稻；水肥“三匀”技术; 产量; 水分生产效率; 氮肥利用效率

\section{Effects of methodical nitrogen-water distribution management on water and nitrogen use efficiency of rice}

YANG Zhi-Yuan ${ }^{1}$, LI Na $^{1}$, MA Peng ${ }^{1}$, YAN Tian-Rong ${ }^{1}$, HE Yan ${ }^{1}$, JIANG Ming-Jin $^{1}$, LYU Teng-Fei ${ }^{1}$, LI Yu $^{1}$, GUO Xiang ${ }^{2}$, HU Rong ${ }^{3}$, GUO Chang-Chun ${ }^{1}$, SUN Yong-Jian ${ }^{1}$, and MA Jun ${ }^{1, *}$

\footnotetext{
${ }^{1}$ Rice Research Institute, Sichuan Agricultural University / Crop Ecophysiology and Cultivation Key Laboratory of Sichuan Province, Chengdu 611130, Sichuan, China; ${ }^{2}$ Sichuan Agro-meteorological Center, Chengdu 610072, Sichuan, China; ${ }^{3}$ High Quality Seed Production Station of Sichuan Province, Chengdu 610210, Sichuan, China
}

\begin{abstract}
This study included three split-plot designed experiments. Experiments 1 and 2 were conducted in two fields with varied soil fertility and consistent treatment. Two rice varieties (Dexiang 4103, high NUE; Yixiang 3724, low NUE) were set as main plot. The sub-plot contained six nitrogen-water management modes (farmer's usual management, FU; nitrogen-water coupling management, NWC; methodical nitrogen-water distribution management, MNWD; and their respective nitrogen-free controls). The main plot of Exp.3 was two high NUE varieties (Dexiang 4103, Fyou 498) and two low NUE varieties (Yixiang 3724, Chuanyou 6203); FU, NWC, and MNWD assembled the sub-plot. MNWD adopted the method of increasing frequency and reducing quantity, thus the nitrogen application rate was reduced by $20 \%$ compared with NWC and FU, the irrigation water amount was reduced by $20 \%$ to $25 \%$ compared with NWC, and $42 \%$ to $48 \%$ compared with FU. The stem number of MNWD changed
\end{abstract}

本研究由国家重点研发计划项目(2017YFD0301701, 2017YFD0301706)和四川省教育厅重点项目(18ZA0390)资助。

This study was supported by the National Key Research and Development Program of China (2017YFD0301701, 2017YFD0301706) and the Key Research Fund of the Education Department of Sichuan Province (18ZA0390).

*通信作者(Corresponding author): 马均, E-mail: majunp2002@163.com, Tel: 028-86290303

第一作者联系方式: E-mail: dreamislasting@163.com, Tel: 028-86290303

Received (收稿日期): 2019-05-10; Accepted (接受日期): 2019-09-26; Published online (网络出版日期): 2019-10-11.

URL: http://kns.cnki.net/kcms/detail/11.1809.S.20191010.1721.006.html 
smoothly and its ear bearing tiller percentage was higher. Compared with NWC and FU, the photo assimilation before anthesis MNWD had less, dry matter transportation before anthesis and high accumulation of assimilate after anthesis. The grain yield of MNWD was similar to that of NWC, while $8.77 \%-14.18 \%$ higher than that of FU. Correlation analysis showed that the dry weight of roots in 10-20 cm and 20-30 cm soil layers were significantly and positively correlated with nitrogen recovery efficiency (NRE), nitrogen agronomy efficiency (NAE), irrigation water production efficiency (IWPE) and water production efficiency (WPE). MNWD had a large amount of root system distributed in the soil layer below $10 \mathrm{~cm}$, which was conducive to the improvement of water and nitrogen utilization efficiency. Compared with NWC and FU, MNWD increased NRE by $8.07 \%-11.99 \%$ and $20.72 \%-30.78 \%$, NAE by $17.44 \%-27.38 \%$ and $96.47 \%-101.42 \%$, IWPE by $23.34 \%-36.67 \%$ and $76.54 \%-117.38 \%$, WPE by $8.41 \%-17.66 \%$ and $32.23 \%-65.29 \%$, respectively.

Keywords: rice; methodical nitrogen-water distribution management; grain yield; water use efficiency; nitrogen use efficiency

中国耕地面积少, 人口数量多, 高产一直是作 物生产研究的首要目标 ${ }^{[1]}$ 。在过去近二十年里, 代表 中国作物生产较高研究水平的水稻栽培取得了较多 的研究成果，农业科技工作者依据不同稻区生态条 件特点, 提出了各具特色的高产栽培技术, 如群体 质量栽培 ${ }^{[2]}$ 、“旺壮重”栽培 ${ }^{[3]}$ 、“三定”栽培 ${ }^{[4]}$ 、有序 摆抛栽 ${ }^{[5]}$ 及 “三角形”栽培 ${ }^{[6]}$ 等。这些高产栽培技术保 证了中国单位面积稻田氮肥投入量在过去近二十年 里基本保持稳定, 但产量有了较大幅度提高, 基本 实现了中国稻米自给。经过多年的高速增长, 中国 水稻持续增产难度越来越大, 而持续高水肥投入带 来的成本压力已经开始挫伤农民的水稻生产积极性, 愈演愈烈的水资源短缺 ${ }^{[7]}$ 和氮面源污染 ${ }^{[8]}$ 问题更是 引发了公众对水稻生产如何发展的关注。目前, 中 国政府正引导农业生产由单纯追求高产向以资源节 约、环境友好为前提的稳产方向发展, 水稻生产发 展要符合国家政策导向、满足农民生产需求, 必须 加强节水减氮技术研究 ${ }^{[9]}$ 。以水肥耦合为核心的节 水节氮技术前人已经进行了较多的研究, 在大田试 验中取得了较好的节水节氮效果 ${ }^{[10-12]}$, 但由于该 技术对水分控制要求较高, 在实际生产中推广应用 存在一定困难。国际水稻研究所提出的 SPAD 指导 施氮技术, 氮肥投入总量较少, 但施用次数多, 且 施氮时间依据叶片氮素状态差异变化较大 ${ }^{[13-14]}$; 中国广泛应用的依据叶龄分次施氮技术，氮肥投入 总量稍多, 但次数少, 且施氮时间依据稻株生育时 期推进相对固定 ${ }^{[15]}$; 我们融合 SPAD 指导施氮少量 多次利用率高及依据叶龄分次施氮时间固定操作 简单的优点, 并结合水肥一体化思路, 提出水肥 “三匀”技术。该技术首先将播栽前、分菜期及孕穗 期等施氮关键时间节点分别向前后适度延伸, 拓展 出新的氮肥投入时间节点, 在水肥一体化前提下, 使水氮投入频率趋于均匀; 其次从总量减少的基
肥、竪肥和穗肥中分别抽出一部分，投入到新的时 间节点, 并将可见水层 $(3 \sim 5 \mathrm{~cm})$ 的高强度漫水灌溉 分散为土壤饱和即止的低强度匀水灌溉, 以满足新 时间节点的需求，使水氮投入数量趋于均匀; 最后 结合水肥一体化高效灌溉设备, 实现以水带肥, 在 土壤恰好饱和的灌溉前提下，一体化投入的水氮在 土壤耕层中的分布趋于均匀。与目前常见的水肥耦 合模式(干湿交替灌溉结合基、莉、穗肥分次施氮) 相比，该技术以减基肥、控藍肥、调穗肥和增粒肥 为核心, 变低频高强度的大水大肥漫灌为高频低强 度的匀水匀肥渗透, 但新时间节点上投入的氮肥能 否更高效地行使原来基、㯺、穗肥的部分功能, 能 否更好地满足水稻不同生育时期对氮素的差异性 需求，以及“三匀”技术采用的灌溉模式能否实现节 水目标等尚缺乏系统研究。本文以农民习惯模式及 由叶龄分次施氮技术发展而来的水肥耦合技术为 对照, 比较水肥“三匀”技术在水稻产量、氮肥利用 效率及水分生产效率三方面的表现，分析其茎菜消 长动态、根系生长分布及干物质积累转运特征, 探 求水肥“三匀”技术促进水稻水肥高效利用的部分 理论支撑, 为水稻绿色高产高效栽培提供理论和技 术依据。

\section{1 材料与方法}

\section{1 试验地点}

四川省成都市温江区四川农业大学水稻研究 所试验农场 $\left(30^{\circ} 43^{\prime} \mathrm{N}, 103^{\circ} 47^{\prime} \mathrm{E}\right)$ 和四川省绵阳市 涪城区西南科技大学试验农场 $\left(31^{\circ} 32^{\prime} \mathrm{N}\right.$, $\left.104^{\circ} 41^{\prime} \mathrm{E}\right)$, 前者地处成都平原, 属亚热带季风性 湿润气候, 雨量充沛, 但光温资源较差; 后者地 处川中丘岭, 属亚热带山地湿润季风气候, 伏旱 频发, 但光温资源较优。2015 年和 2017 年水稻 季气象数据均来自四川省气象局(表 1)。2015 年 
进行 2 个大田试验(试验 1 和试验 2), 前茬均为油 菜, 土壤质地为沙壤土, 4 月 7 日播种, 5 月 8 日移 栽, 9 月 10 日收获; 2017 年进行 1 个大田试验(试
验 3), 前茬为小麦, 土壤质地为黏壤土, 4 月 28 日播种, 5 月 26 日移栽, 9 月 26 日收获; 试验田块 耕层土壤养分含量见表 2 。

表 1 两个试验点水稻生长期间气象条件

Table 1 Meteorological conditions of the two experimental locations

\begin{tabular}{ccccc}
\hline $\begin{array}{c}\text { 地点 } \\
\text { Location }\end{array}$ & $\begin{array}{c}\text { 年份 } \\
\text { Year }\end{array}$ & $\begin{array}{c}\text { 全生育期降雨量 } \\
\text { Total rainfall of WGS } \\
(\mathrm{mm})\end{array}$ & $\begin{array}{c}\text { 全生育期日照时数 } \\
\text { Total sunshine hours of WGS } \\
(\mathrm{h})\end{array}$ & $\begin{array}{c}\text { 全生育期日平均温度 } \\
\text { Average diurnal temperature of WGS } \\
\left({ }^{\circ} \mathrm{C}\right)\end{array}$ \\
\hline 温江 Wenjiang & 2015 & 538.8 & 630.3 & 22.32 \\
涪城 Fucheng & 2017 & 426.0 & 757.3 & 23.88 \\
\hline
\end{tabular}

WGS: 全生育期。WGS: whole growth stage.

表 22015 年和 2017 年耕层土壤养分含量表

Table 2 Average values for selected soil characteristics of composite topsoil samples $(0-20 \mathrm{~cm})$ from the experimental fields in 2015 and 2017

\begin{tabular}{cccccc}
\hline $\begin{array}{c}\text { 试验 } \\
\text { Experiment }\end{array}$ & $\begin{array}{c}\text { 有机质 } \\
\text { Organic matter }\left(\mathrm{g} \mathrm{kg}^{-1}\right)\end{array}$ & $\begin{array}{c}\text { 全氮 } \\
\text { Total N }\left(\mathrm{g} \mathrm{kg}^{-1}\right)\end{array}$ & $\begin{array}{c}\text { 速效氮 } \\
\text { Available N }\left(\mathrm{mg} \mathrm{kg}^{-1}\right)\end{array}$ & $\begin{array}{c}\text { 速效磷 } \\
\text { Available } \mathrm{P}\left(\mathrm{mg} \mathrm{kg}^{-1}\right)\end{array}$ & $\begin{array}{c}\text { 速效钾 } \\
\mathrm{Available} \mathrm{K}\left(\mathrm{mg} \mathrm{kg}^{-1}\right)\end{array}$ \\
\hline 试验 1 Exp.1 & 16.57 & 1.47 & 76.46 & 14.42 & 79.13 \\
试验 2 Exp.2 & 26.41 & 2.03 & 109.65 & 29.57 & 110.48 \\
试验 3 Exp.3 & 22.08 & 1.79 & 100.33 & 21.83 & 98.36 \\
\hline
\end{tabular}

\section{2 供试材料}

以前期大田试验篮选出的在氮肥利用效率上有 显著差异的品种为供试材料 ${ }^{[10]}$ 。2015 年 2 个杂交稻 品种, 即氮高效品种德香 4103 (D4103)和氮低效品 种宜香 3724 (Y3724)。2017 年 4 个杂交稻品种, 即 氮高效品种德香 4103、F 优 498 (F498)及氮低效品 种宜香 3724、川优 6203 (C6203)。4 个品种均为中 籼迟熟杂交稻, 生育期差异小于 $3 \mathrm{~d}$ 。

\section{3 试验设计}

2015 年进行的试验 1 和试验 2 土壤基础肥力存 在较大差异, 试验处理完全一致, 为水稻品种 $\times$ 水氮 处理二因素随机区组试验。6 种水氮处理分别为农 民习惯模式、水肥耦合模式和水肥“三匀”模式 3 种 水氮管理模式及各自水分管理相同但不施氮肥的对 照处理(表 3), 共计 12 个处理, 3 次重复, 单个小区 面积为 $3.5 \mathrm{~m} \times 4.0 \mathrm{~m}=14.0 \mathrm{~m}^{2}$ 。

2017 年进行的试验 3 亦为水稻品种 $\times$ 水氮处理 2 因素随机区组试验。水稻品种数量增为 4 个, 水氮 处理减为 3 种, 分别为优化施氮模式、水肥耦合模 式和水肥“三匀”模式, 共计 12 个处理, 3 次重复, 单 个小区面积为 $4.5 \mathrm{~m} \times 5.0 \mathrm{~m}=22.5 \mathrm{~m}^{2}$ 。

4 个试验小区内水稻移栽密度均为 $33.3 \mathrm{~cm} \times 16.7 \mathrm{~cm}$, 田间灌溉水量用水表计量。除氮肥外, $75 \mathrm{~kg} \mathrm{hm}^{-2}$
$\mathrm{P}_{2} \mathrm{O}_{5}$ 和 $150 \mathrm{~kg} \mathrm{hm}^{-2} \mathrm{~K}_{2} \mathrm{O}$ 均作基肥施用。试验所用氮、 磷、钾肥分别为尿素( 含 $\mathrm{N} 46 \%$ )、过磷酸钙(含 $\mathrm{P}_{2} \mathrm{O}_{5} 12 \%$ ) 和氯化钾(含 $\mathrm{K}_{2} \mathrm{O} 60 \%$ )。试验期间进行合理的田间管 理, 整个生育期没有明显的涝害、旱害和病虫草害。

\section{4 测定项目与方法}

1.4.1 茎藥动态变化试验 $1 、 2$ 和 3 均于移栽后 1 周开始,每 $7 \mathrm{~d}$ 从每小区选择长势均匀水稻 15 株记 录茎藍数, 至抽穗后停止。

1.4.2 根系生长分布测定于拔节期和抽穗期, 按平均茎藮数标记每小区 3 株具有代表性稻株, 采 用原状土柱法, 用铁锹以稻株为中心掘取长等于行 距, 宽等于株距, 深 $30 \mathrm{~cm}$ 的土柱, 将挖出的根系土 层按 $0 \sim 10 \mathrm{~cm} 、 10 \sim 20 \mathrm{~cm}$ 和 $20 \sim 30 \mathrm{~cm}$ 分为 3 个部分, 用高压雾化洗根器洗去泥土杂质后于 $80^{\circ} \mathrm{C}$ 下烘干至 恒重, 测得各土层根干重。

1.4.3 千物质及氮素积累测定将抽穗期根系形 态指标测定剩余的地上部烘干后称质量; 成熟期从 每小区按平均有效穗数标记 3 株, 取地上部分烘干、 称质量、粉碎并过篮，用凯氏定氮仪(FOSS-8400)测 定全氮含量。

1.4.4 考种与计产成熟期从每小区按平均有效 穗数取样 5 株, 考察穗粒结构; 剩余部分单独收割, 按实收株数计产。 


\section{表 3 水氮管理模式}

Table 3 Nitrogen-water management mode

\begin{tabular}{|c|c|c|}
\hline $\begin{array}{c}\text { 水氮管理模式 } \\
\text { Nitrogen-water } \\
\text { management mode }\end{array}$ & $\begin{array}{c}\text { 氮肥管理 } \\
\text { Nitrogen management }\end{array}$ & $\begin{array}{c}\text { 水分管理 } \\
\text { Water management }\end{array}$ \\
\hline $\begin{array}{c}\text { 农民习惯模式 } \\
\text { FU }\end{array}$ & 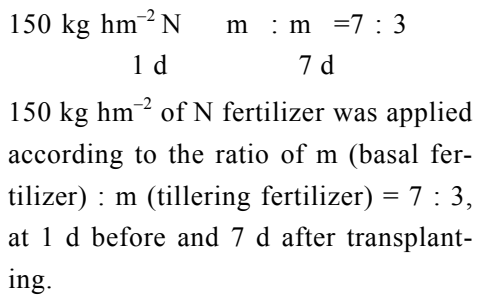 & $\begin{array}{l}\text { 淹水灌溉: 水稻移栽后田面一直保持 } 1 \sim 3 \mathrm{~cm} \text { 水层, 收获前 } 1 \text { 周自然 } \\
\text { 落干。 } \\
\text { Flood irrigation: after rice transplanting, a 1-3 cm water layer was always } \\
\text { maintained above the surface of the paddy fields and dried naturally at } 1 \\
\text { week before harvest. }\end{array}$ \\
\hline $\begin{array}{c}\text { 农民习惯模式对照 } \\
\text { CTF }\end{array}$ & $\begin{array}{l}\text { 水稻季不施 } \mathrm{N} 。 \\
\text { No } \mathrm{N} \text { was applied in rice season. }\end{array}$ & $\begin{array}{l}\text { 淹水灌溉。 } \\
\text { Flood irrigation. }\end{array}$ \\
\hline $\begin{array}{c}\text { 水肥耦合模式 } \\
\text { NWC }\end{array}$ & 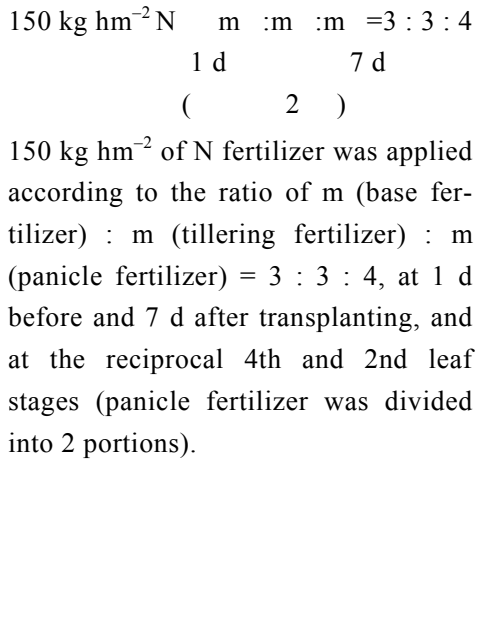 & $\begin{array}{l}\text { 控制性灌溉: 浅水 }(1 \mathrm{~cm} \text { 左右)栽秧, 移栽后 } 5 \sim 7 \mathrm{~d} \text { 田间保持 } 2 \mathrm{~cm} \text { 水层 } \\
\text { 确保秧苗返青成活, 之后至孕穗前田面不保持水层, 土壤含水量为 } \\
\text { 饱和含水量的 } 70 \% \sim 80 \% \text {, 无效分櫱期晒田; 孕穗期土表保持 } 1 \sim 3 \mathrm{~cm} \\
\text { 水层; 抽穗至成熟期采用灌透水、自然落干至土壤水势为 }-25 \mathrm{kPa} \text { 时 } \\
\text { 再灌水。 } \\
\text { Controlled irrigation: transplanting was done in shallow water }(\sim 1 \mathrm{~cm}) \text {, } \\
\text { a } 2 \mathrm{~cm} \text { water layer was maintained in the fields to } 5-7 \mathrm{~d} \text { after trans- } \\
\text { planting to ensure that the seedlings turned green and survival, after } \\
\text { that, drained surface water and maintained a soil moisture of } 70 \%-80 \% \\
\text { of saturated water content before booting stage, the fields were dried } \\
\text { during the ineffective tillering stage, a } 1-3 \mathrm{~cm} \text { water layer was main- } \\
\text { tained above the soil surface during the booting stage, and performed } \\
\text { alternate wetting and drying irrigation from heading to maturity (irri- } \\
\text { gated to } 1-3 \mathrm{~cm} \text { water and dried naturally to the soil water potential of } \\
-25 \mathrm{kPa} \text {. }\end{array}$ \\
\hline
\end{tabular}

$\begin{array}{cl}\text { 水肥耦合模式对照 } & \text { 水稻季不施 } \mathrm{N} \text { 。 } \\ \text { CTN } & \text { No N was applied in rice season. } \\ \text { 水肥“三匀”模式 } & 15 、 15 、 30 、 15 、 15 、 15 \text { 和 } 15 \mathrm{~kg} \mathrm{hm}^{-2} \\ \text { MNWD } & \text { (合计 } 120 \mathrm{~kg} \mathrm{hm}^{-2} \text { ) N 分别于移栽后 } \\ & 7 、 14 、 35 、 49 、 56 、 70 \text { 和 } 77 \mathrm{~d} \text { 施用。 } \\ & 15,15,30,15,15,15, \text { and } 15 \mathrm{~kg} \mathrm{hm}^{-2} \\ & \text { (total 120 kg hm-2) of N fertilizer were } \\ & \text { applied at } 7,14,35,49,56,70, \text { and } 77 \\ & \text { d after transplanting. }\end{array}$

控制性灌溉。

Controlled irrigation.

“匀水”管理: 浅水 $(1 \mathrm{~cm}$ 左右)栽种, 随后利用水肥一体化设备将施肥 与灌水同步进行, 若灌水施肥时田面有水层则灌水量以水面升高 1 $\mathrm{cm}$ 左右为宜, 若灌水施肥时田面无水层则灌水至土壤饱和即可; 非 施肥时间段若田面裂口超过 $2 \mathrm{~cm}$ 亦补灌至土壤饱和。

Uniform water management: transplanting was done in shallow water $(\sim 1 \mathrm{~cm})$, nitrogen-water synchronization equipment was used to fertilize and irrigate the fields simultaneously, if there was already a water layer in the fields, the amount of irrigation water applied increased the layer by $\sim 1 \mathrm{~cm}$. If there was no existing water layer, irrigation was done until soil saturation, during non-fertilizing periods, irrigation water was replenished until soil saturation whenever the fields' surface cracks larger than $2 \mathrm{~cm}$ appeared.

\section{“匀水”管理。 \\ Uniform water management. \\ 水肥“三匀”模式对照 水稻季不施 N。 \\ CTM No N was applied in rice season.}

FU：农民习惯模式; CTF：农民习惯模式对照; NWC：水肥耦合模式; CTN：水肥塊合模式对照; MNWD：水肥“三匀”模式; CTM：水肥 “三匀”模式对照。

FU: farmer's usual management; CTF: control treatment of FU; NWC: nitrogen-water coupling management; CTN: control treatment of NWC; MNWD: methodical nitrogen-water distribution management; CTM: control treatment of MNWD. 


\section{5 数据处理及指标计算}

用 Microsoft Excel 和 SPSS 20 统计分析数据, 用 Origin 9 作图。

氮素积累总量(total nitrogen accumulation, TNA) $=$ 成熟期单位面积稻株地上部氮积累量

氮肥农学利用率(nitrogen agronomy efficiency, $\mathrm{NAE})=($ 施氮区产量-对照处理产量 $) /$ 施氮量

氮肥回收利用率 (nitrogen recovery efficiency, $\mathrm{NRE})=($ 施氮区氮素积累总量-对照处理氮素积累总 量 $) /$ 施氮量 $\times 100 \%$

灌溉水生产效率 (irrigation water production efficiency, IWPE) $=$ 稻谷产量/灌溉水量

水分生产效率(water production efficiency, WPE) = 水稻产量/(生育期降雨量+灌溉水用量)

\section{2 结果与分析}

2.1 水氮管理对不同氮效率水稻产量及物质生 产转运的影响

由表 4 可见, 不同氮效率水稻品种产量存在显 著差异, 氮高效品种德香 4103 (D4103)较氮低效品 种宜香 3724 (Y3724)有 $15.56 \%$ (低肥力土壤)和 $13.20 \%$ (高肥力土壤)的产量优势。水肥“三匀”模式
(MNWD)和水肥耦合模式(NWC)水稻产量相近, 均 显著高于农民习惯模式(FU); 低肥力条件下, 采 用淹水管理的农民习惯模式对照(CTF)产量最高, 采用控制性灌水管理的水肥耦合模式对照 (CTN) 次之, 采用“匀水”管理的水肥“三匀”模式对照 (CTM)最低，显著低于 CTF (5.04\%); 高肥力条件 下, 则以 $\mathrm{CTM}$ 产量最高, $\mathrm{CTF}$ 最低, 差异显著 $(4.89 \%)$ 。 与产量差异不显著的 NWC 相比, MNWD 花前物质积 累量低, 籽粒灌浆期向穗部转运亦少, 导致其收获指 数不高, 但 MNWD 花后光合生产优势显著, 确保其在 减氮 $20 \%\left(120 \mathrm{~kg} \mathrm{hm}^{-2}\right.$ 与 $\left.150 \mathrm{~kg} \mathrm{hm}^{-2}\right)$ 条件下产量不 降低。

如表 5 所示, 在光温条件优越的涪城试验点, 氮高效品种产量仍显著高于氮低效品种 $(14.08 \%$ $14.80 \%)$ 。MNWD 产量与 NWC 差异不显著, 分别较 FU 提高 $13.95 \%$ 和 $12.94 \%$ 。MNWD 花前物质积累及 转运均显著低于 NWC, 但其花后光合生产强劲, 推 动总干物质积累表现出较大优势, 在收获指数偏低 的情况下，产量不低于 $\mathrm{NWC}^{\circ}$

3 个试验中, 品种类型与水肥管理模式互作均 未显著影响水稻产量, 表明减氮稳产的 MNWD 模 式效果较稳定, 通用性较强。

表 4 水氮管理对不同氮效率水稻产量及物质生产转运的影响(温江, 2015)

Table 4 Effects of nitrogen-water management modes on yield and assimilate production and transportation of hybrid rice with different $\mathrm{N}$ use efficiencies (Wenjiang, 2015)

\begin{tabular}{|c|c|c|c|c|c|c|c|c|}
\hline $\begin{array}{c}\text { 试验 } \\
\text { Experiment }\end{array}$ & $\begin{array}{l}\text { 因素 } \\
\text { Factor }\end{array}$ & $\begin{array}{c}\text { 处理 } \\
\text { Treatment }\end{array}$ & $\begin{array}{c}\text { 花前干物质积累 } \\
\text { DMBF } \\
\left(\mathrm{kg} \mathrm{hm}^{-2}\right)\end{array}$ & $\begin{array}{c}\text { 花后干物质积累 } \\
\text { DMAF } \\
\left(\mathrm{kg} \mathrm{hm}^{-2}\right) \\
\end{array}$ & $\begin{array}{c}\text { 总干物质积累 } \\
\text { TDM } \\
\left(\mathrm{kg} \mathrm{hm}^{-2}\right) \\
\end{array}$ & $\begin{array}{c}\text { 花前物质转运 } \\
\text { TDMBF } \\
\left(\mathrm{kg} \mathrm{hm}^{-2}\right) \\
\end{array}$ & $\begin{array}{c}\text { 收获指数 } \\
\mathrm{HI} \\
(\%) \\
\end{array}$ & $\begin{array}{c}\text { 产量 } \\
\text { Yield } \\
\left(\mathrm{kg} \mathrm{hm}^{-2}\right) \\
\end{array}$ \\
\hline 试验 1 & 品种 & D4103 & $9730 \mathrm{a}$ & $4504 \mathrm{a}$ & $14234 \mathrm{a}$ & $2828 \mathrm{a}$ & $51.89 \mathrm{a}$ & 8476 a \\
\hline $\begin{array}{l}\text { Exp.1 } \\
\text { (低肥力 }\end{array}$ & Cultivar (C) & Y3724 & $8352 \mathrm{~b}$ & 4079 a & $12431 \mathrm{~b}$ & 2266 a & $51.40 \mathrm{a}$ & $7335 \mathrm{~b}$ \\
\hline \multirow{9}{*}{$\begin{array}{c}\text { 土壤 Low } \\
\text { fertility soil) }\end{array}$} & 氮肥管理 & $\mathrm{CTF}$ & $7169 \mathrm{~d}$ & $4116 \mathrm{c}$ & $11285 \mathrm{c}$ & $1788 \mathrm{~d}$ & $52.31 \mathrm{bc}$ & $6826 \mathrm{c}$ \\
\hline & $\begin{array}{c}\text { Nitrogen } \\
\text { management }(\mathrm{N})\end{array}$ & FU & $10608 \mathrm{c}$ & $3870 \mathrm{~cd}$ & $14478 \mathrm{~b}$ & 3593 a & $51.52 \mathrm{c}$ & $8627 \mathrm{~b}$ \\
\hline & & $\mathrm{CTN}$ & $7112 \mathrm{~d}$ & $3471 \mathrm{~d}$ & $10583 \mathrm{~d}$ & $2267 \mathrm{c}$ & $54.19 \mathrm{a}$ & $6633 \mathrm{~cd}$ \\
\hline & & NWC & 11672 a & $4880 \mathrm{~b}$ & 16523 a & $3321 \mathrm{a}$ & $49.56 \mathrm{~d}$ & 9481 a \\
\hline & & CTM & $6425 \mathrm{e}$ & $4089 \mathrm{c}$ & $10514 \mathrm{~d}$ & $1518 \mathrm{~d}$ & $53.36 \mathrm{ab}$ & $6482 \mathrm{~d}$ \\
\hline & & MNWD & $11262 \mathrm{~b}$ & $5322 \mathrm{a}$ & $16584 \mathrm{a}$ & $2795 \mathrm{~b}$ & $48.94 \mathrm{~d}$ & 9384 a \\
\hline & $F$ 值 & $\mathrm{C}$ & $627.67^{* *}$ & $7.50^{\mathrm{NS}}$ & $109.66^{* *}$ & $12.21^{*}$ & $0.39^{\mathrm{NS}}$ & $1857.57^{* *}$ \\
\hline & $F$-value & $\mathrm{N}$ & $709.04^{* *}$ & $24.34^{* *}$ & $619.84^{* *}$ & $41.51^{* *}$ & $14.19^{* *}$ & $453.60^{* *}$ \\
\hline & & $\mathrm{N}^{*} \mathrm{C}$ & $4.63^{* *}$ & $0.37^{\mathrm{NS}}$ & $1.52^{\mathrm{NS}}$ & $1.00^{\mathrm{NS}}$ & $0.51^{\mathrm{NS}}$ & $0.88^{\mathrm{NS}}$ \\
\hline
\end{tabular}


(续表 4)

\begin{tabular}{|c|c|c|c|c|c|c|c|c|}
\hline $\begin{array}{c}\text { 试验 } \\
\text { Experiment }\end{array}$ & $\begin{array}{l}\text { 因素 } \\
\text { Factor }\end{array}$ & $\begin{array}{c}\text { 处理 } \\
\text { Treatment }\end{array}$ & $\begin{array}{c}\text { 花前干物质积累 } \\
\text { DMBF } \\
\left(\mathrm{kg} \mathrm{hm}^{-2}\right)\end{array}$ & $\begin{array}{c}\text { 花后干物质积累 } \\
\text { DMAF } \\
\left(\mathrm{kg} \mathrm{hm}^{-2}\right)\end{array}$ & $\begin{array}{c}\text { 总干物质积累 } \\
\text { TDM } \\
\left(\mathrm{kg} \mathrm{hm}^{-2}\right)\end{array}$ & $\begin{array}{c}\text { 花前物质转运 } \\
\text { TDMBF } \\
\left(\mathrm{kg} \mathrm{hm}^{-2}\right)\end{array}$ & $\begin{array}{c}\text { 收获指数 } \\
\text { HI } \\
(\%) \\
\end{array}$ & $\begin{array}{c}\text { 产量 } \\
\text { Yield } \\
\left(\mathrm{kg} \mathrm{hm}^{-2}\right)\end{array}$ \\
\hline 试验 2 & 品种 & D4103 & $10975 \mathrm{a}$ & $5605 \mathrm{a}$ & $16570 \mathrm{a}$ & 2697 a & $51.41 \mathrm{a}$ & 9598 a \\
\hline $\begin{array}{c}\text { Exp.2 } \\
\text { (高肥力 }\end{array}$ & Cultivar (C) & Y3724 & $9572 \mathrm{~b}$ & $4760 \mathrm{~b}$ & $14332 \mathrm{~b}$ & $2575 \mathrm{a}$ & $50.42 \mathrm{a}$ & $8479 \mathrm{~b}$ \\
\hline \multirow{9}{*}{$\begin{array}{c}\text { 土壤 High } \\
\text { fertility soil) }\end{array}$} & 氮肥管理 & CTF & $8220 \mathrm{c}$ & $4542 \mathrm{~d}$ & $12762 \mathrm{~d}$ & $2103 \mathrm{c}$ & $52.18 \mathrm{a}$ & $7683 \mathrm{~d}$ \\
\hline & $\begin{array}{c}\text { Nitrogen } \\
\text { management }(\mathrm{N})\end{array}$ & FU & $11438 \mathrm{~b}$ & $4376 \mathrm{~d}$ & $15814 \mathrm{~b}$ & 3666 a & $50.88 \mathrm{ab}$ & $9297 \mathrm{~b}$ \\
\hline & & $\mathrm{CTN}$ & $8414 \mathrm{c}$ & $4690 \mathrm{~cd}$ & $13104 \mathrm{~cd}$ & $2170 \mathrm{bc}$ & $52.34 \mathrm{a}$ & $7930 \mathrm{c}$ \\
\hline & & NWC & $12832 \mathrm{a}$ & $5811 \mathrm{~b}$ & $18643 \mathrm{a}$ & $3383 \mathrm{a}$ & $49.35 \mathrm{bc}$ & $10629 \mathrm{a}$ \\
\hline & & CTM & $8138 \mathrm{c}$ & $5199 \mathrm{c}$ & $13337 \mathrm{c}$ & $1789 \mathrm{c}$ & $52.42 \mathrm{a}$ & $8078 \mathrm{c}$ \\
\hline & & MNWD & $12570 \mathrm{a}$ & $6477 \mathrm{a}$ & $19047 \mathrm{a}$ & $2705 \mathrm{~b}$ & $48.30 \mathrm{c}$ & $10615 \mathrm{a}$ \\
\hline & $F$ 值 & $\mathrm{C}$ & $10239.23^{* *}$ & $34.95^{*}$ & $274.65^{* *}$ & $1.04^{\mathrm{NS}}$ & $4.68^{\mathrm{NS}}$ & $168.41^{* *}$ \\
\hline & $F$-value & $\mathrm{N}$ & $551.69^{* *}$ & $17.95^{* *}$ & $403.04^{* *}$ & $16.38^{* *}$ & $9.54^{* *}$ & $264.27^{* *}$ \\
\hline & & $\mathrm{N}^{*} \mathrm{C}$ & $1.93^{\mathrm{NS}}$ & $1.80^{\mathrm{NS}}$ & $4.26^{* *}$ & $1.37^{\mathrm{NS}}$ & $1.32^{\mathrm{NS}}$ & $1.24^{\mathrm{NS}}$ \\
\hline
\end{tabular}

D4103：德香 4103; Y3724：宜香 3724; CTF：农民习惯模式对照; FU：农民习惯模式; CTN：水肥耦合模式对照; NWC：水肥耦合模式; CTM：水肥“三匀”模式对照; MNWD：水肥“三匀”模式; DMBF：花前干物质积累; DMAF：花后干物质积累; TDM：总干物质积累; TDMBF: 花前物质转运; HI: 收获指数。同一列数据后不同小写字母表示不同品种间或不同施肥处理间在 0.05 水平差异显著。

Y3724: Yixiang 3724; D4103: Dexiang 4103; DMBF: dry matter before flowering; DMAF: dry matter after flowering; TDM: total dry matter; TDMBF: transportation of dry matter before flowering; HI: harvest index. FU: farmer's usual management; CTF: control treatment of FU; NWC: nitrogen-water coupling management; CTN: control treatment of NWC; MNWD: methodical nitrogen-water distribution management; CTM: control treatment of MNWD. Values within a column followed by different letters are significantly different at $P<0.05$ between cultivars or treatments. ${ }^{\mathrm{NS}} P \geq 0.05 ;{ }^{* *} P<0.01 ;{ }^{*} P<0.05$.

表 5 水氮管理对不同氮效率水稻产量及物质生产转运的影响(试验 3: 涪城, 2017)

Table 5 Effects of nitrogen-water management modes on yield and dry matter production and transportation of hybrid rice with different $\mathrm{N}$ use efficiencies (Exp. 3: Fucheng, 2017)

\begin{tabular}{|c|c|c|c|c|c|c|c|}
\hline $\begin{array}{l}\text { 因素 } \\
\text { Factor }\end{array}$ & $\begin{array}{c}\text { 处理 } \\
\text { Treatment }\end{array}$ & $\begin{array}{c}\text { 花前干物质积累 } \\
\text { DMBF } \\
\left(\mathrm{kg} \mathrm{hm}^{-2}\right)\end{array}$ & $\begin{array}{c}\text { 花后干物质积累 } \\
\text { DMAF } \\
\left(\mathrm{kg} \mathrm{hm}^{-2}\right)\end{array}$ & $\begin{array}{c}\text { 总干物质积累 } \\
\text { TDM } \\
\left(\mathrm{kg} \mathrm{hm}^{-2}\right) \\
\end{array}$ & $\begin{array}{c}\text { 花前物质转运 } \\
\text { TDMBF } \\
\left(\mathrm{kg} \mathrm{hm}^{-2}\right) \\
\end{array}$ & $\begin{array}{c}\text { 收获指数 } \\
\text { HI } \\
(\%) \\
\end{array}$ & $\begin{array}{c}\text { 产量 } \\
\text { Yield } \\
\left(\mathrm{kg} \mathrm{hm}^{-2}\right)\end{array}$ \\
\hline 品种 & D4103 & 12050 a & 5682 a & $17732 \mathrm{a}$ & 3457 a & $51.57 \mathrm{a}$ & $10565 \mathrm{a}$ \\
\hline \multirow[t]{3}{*}{ Cultivar (C) } & F498 & $12173 \mathrm{a}$ & 5668 a & $17441 \mathrm{a}$ & 3513 a & $52.72 \mathrm{a}$ & $10613 \mathrm{a}$ \\
\hline & Y3724 & $10525 \mathrm{~b}$ & $4733 \mathrm{~b}$ & $15258 \mathrm{~b}$ & 3264 a & $52.47 \mathrm{a}$ & $9245 \mathrm{~b}$ \\
\hline & C6203 & $10437 \mathrm{~b}$ & $4810 \mathrm{~b}$ & $15247 \mathrm{~b}$ & $3200 \mathrm{a}$ & $52.55 \mathrm{a}$ & $9261 \mathrm{~b}$ \\
\hline 氮肥管理 & $\mathrm{FU}$ & $10635 \mathrm{c}$ & $4297 \mathrm{c}$ & $14932 \mathrm{c}$ & $3579 \mathrm{a}$ & $52.78 \mathrm{a}$ & $9105 \mathrm{~b}$ \\
\hline \multirow{2}{*}{$\begin{array}{c}\text { Nitrogen } \\
\text { management }(\mathrm{N})\end{array}$} & NWC & $11811 \mathrm{a}$ & $5137 \mathrm{~b}$ & $16948 \mathrm{~b}$ & $3758 \mathrm{a}$ & $52.49 \mathrm{a}$ & $10283 \mathrm{a}$ \\
\hline & MNWD & $11443 \mathrm{~b}$ & 5936 a & 17389 a & $3039 \mathrm{~b}$ & $51.72 \mathrm{a}$ & $10375 \mathrm{a}$ \\
\hline$F$ 值 & $\mathrm{C}$ & $21.36^{* *}$ & $6.11^{* *}$ & $23.52^{* *}$ & $1.53^{\mathrm{NS}}$ & $0.51^{\mathrm{NS}}$ & $31.53^{* *}$ \\
\hline \multirow[t]{2}{*}{$F$-value } & $\mathrm{N}$ & $39.40^{* *}$ & $1.33^{\mathrm{NS}}$ & $18.92^{* *}$ & $0.85^{\mathrm{NS}}$ & $0.37^{\mathrm{NS}}$ & $28.11^{* *}$ \\
\hline & $\mathrm{N}^{*} \mathrm{C}$ & $0.19^{\mathrm{NS}}$ & $0.05^{\mathrm{NS}}$ & $0.08^{\mathrm{NS}}$ & $0.12^{\mathrm{NS}}$ & $0.26^{\mathrm{NS}}$ & $0.32^{\mathrm{NS}}$ \\
\hline
\end{tabular}

F498: F 优 498; C6203: 川优 6203。缩写同表 4。同一列数据后不同小写字母表示不同品种间或不同施肥处理间在 0.05 水平差异显著。 F498: Fyou 498; C6203: Chuanyou 6203. Abbreviations are the same as those given in Table 4. Values within a column followed by different letters are significantly different at $P<0.05$ between cultivars or treatments. ${ }^{\mathrm{NS}} P \geq 0.05 ;{ }^{* *} P<0.01 ;{ }^{*} P<0.05$. 


\section{2 水氮管理对不同氮效率水稻茎蒒消长的影响}

如图 1 和图 2 所示, 氮高效品种高峰苗数量多, 最终有效穗数也较氮低效品种有较大优势。2015 年试验中的 3 类空白对照, CTM 高峰苗数量较多, 且出现时间较迟, CTF 高峰苗出现最早, 但数量较 少; 低肥力条件下, CTN 高峰苗出现时间段与 CTF 相近, 而高肥力条件下, 则与 CTM 较一致。施氮处 理中, FU 高峰苗出现时间最早, 数量最多, 随后无 效分乑快速消亡, 最终成穗数量较少, 速升速降特 征明显; MNWD 高峰苗出现时间最迟, 数量最少 (试验 1 的 D4103 除外), 且高峰苗所处的移栽后 35 49 d 时间段内, 茎藍消长较慢, 分葟数量变化 平稳, 缓升缓降特点突出; $\mathrm{NWC}$ 茎藍消长特点介于 FU 和 MNWD之间, 分樫发生速度慢于 FU, 但消亡 速度快于 MNWD, 其有效穗数量显著高于 FU, 与 MNWD 接近。

2.3 水氮管理对不同氮效率水稻根系生长和分 布的影响

抽穗期不同土层根干重较拔节期均有较大幅度 增长, 尤其是 20 30 cm 土层, 表明根系下扎程度加 深(图 3 和图 4)。不施氮处理中, “匀水”灌溉的 CTM
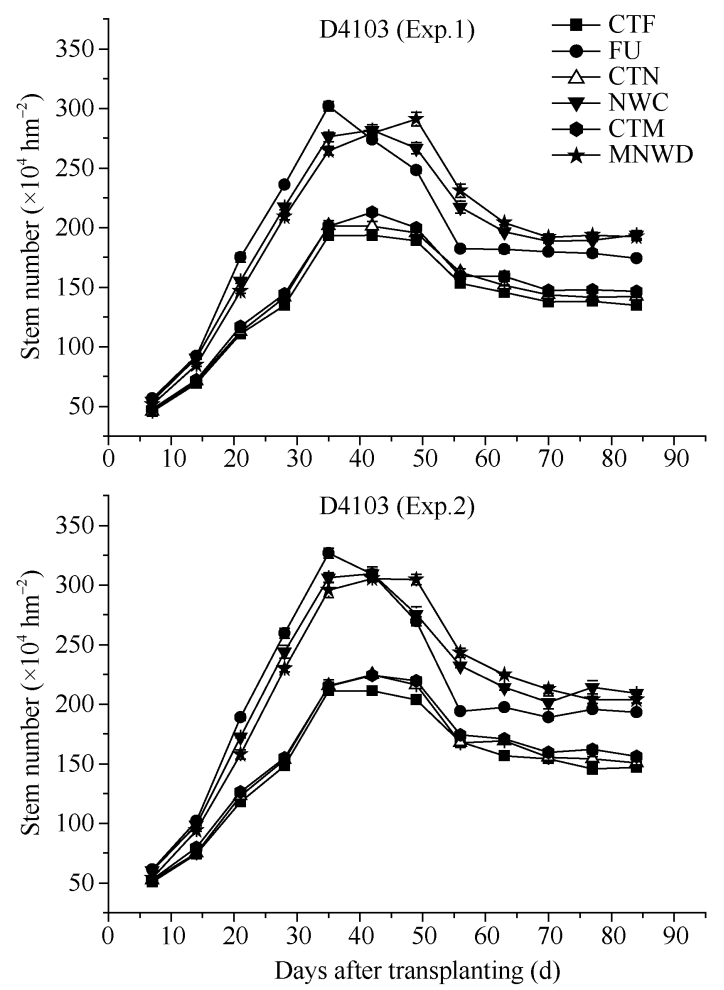

图 1 不同氮效率水稻差异型水氮管理条件下茎菜动态(温江, 2015)

Fig. 1 Stem dynamics of hybrid rice with different $\mathrm{N}$ use efficiencies under varied nitrogen-water management modes (Wenjiang, 2015)

缩写同表 4。Abbreviations are the same as those given in Table 4.
在 20 30 cm 土层中根系最发达, 控制性灌溉的 CTN 土层根干重均较低，NWC 表层土壤根干重与 MNWD 差异较小, 但其 $10 \mathrm{~cm}$ 以下土层根系, 特别 是 20 30 cm 土层根系不如 MNWD 发达; 在 3 个试 验中, 水稻根系在各个土层的分布均以 MNWD 最 发达, 且以 $20 \sim 30 \mathrm{~cm}$ 土层最为明显, 表现出根量 大、扎根深的特点。

2.4 水氮管理对不同氮效率水稻水、氮吸收利用 的影响

由表 6 可见, 氮高效品种总吸氮量显著高于氮 低效品种, 氮肥回收率和农学利用率虽在统计学上 不存在显著差异，但前者仍较后者平均提高 $7.62 \% \sim 13.18 \%$ 。 NWC 总吸氮量最高, MNWD 次之, 农民习惯施肥模式氮积累最少。就氮肥利用效率而 言, MNWD 氮肥回收率和农学利用率最高, 显著高 于 NWC 和 FU, MNWD 的农学利用率较 FU 高出 1 倍左右。无论氮素积累还是氮肥利用效率, 均不受 品种和水氮管理措施的互作效应影响, 表明 MNWD 在提高氮肥增产效果, 减少氮肥损失方面的优势较 稳定，不易受其他因素干扰。

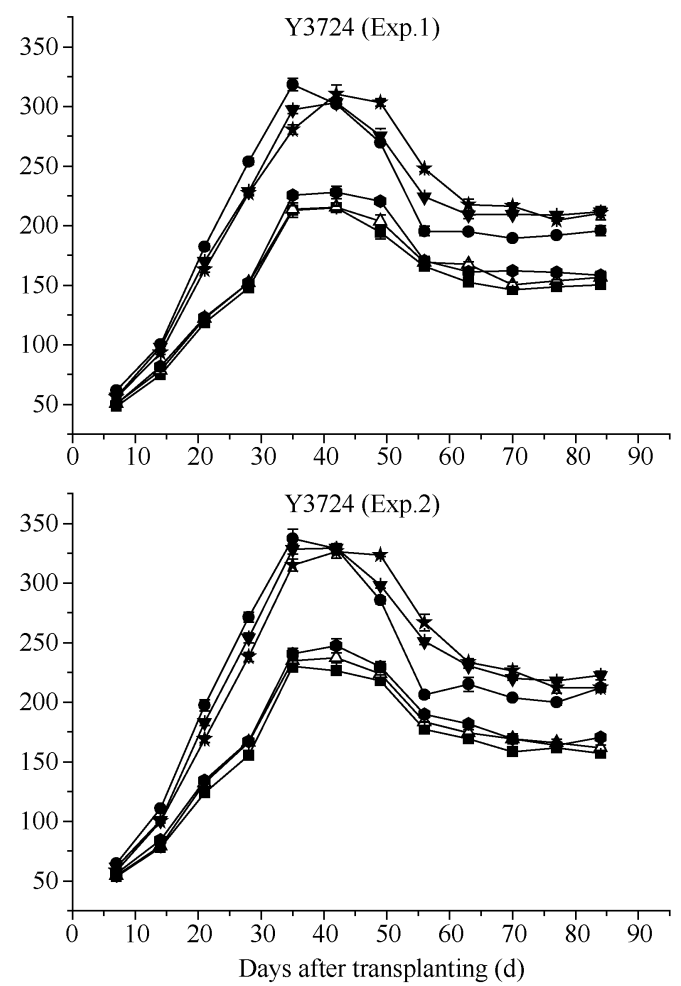
次之, 淹水灌溉的 CTF 最少; 施氮处理中, FU 各个 

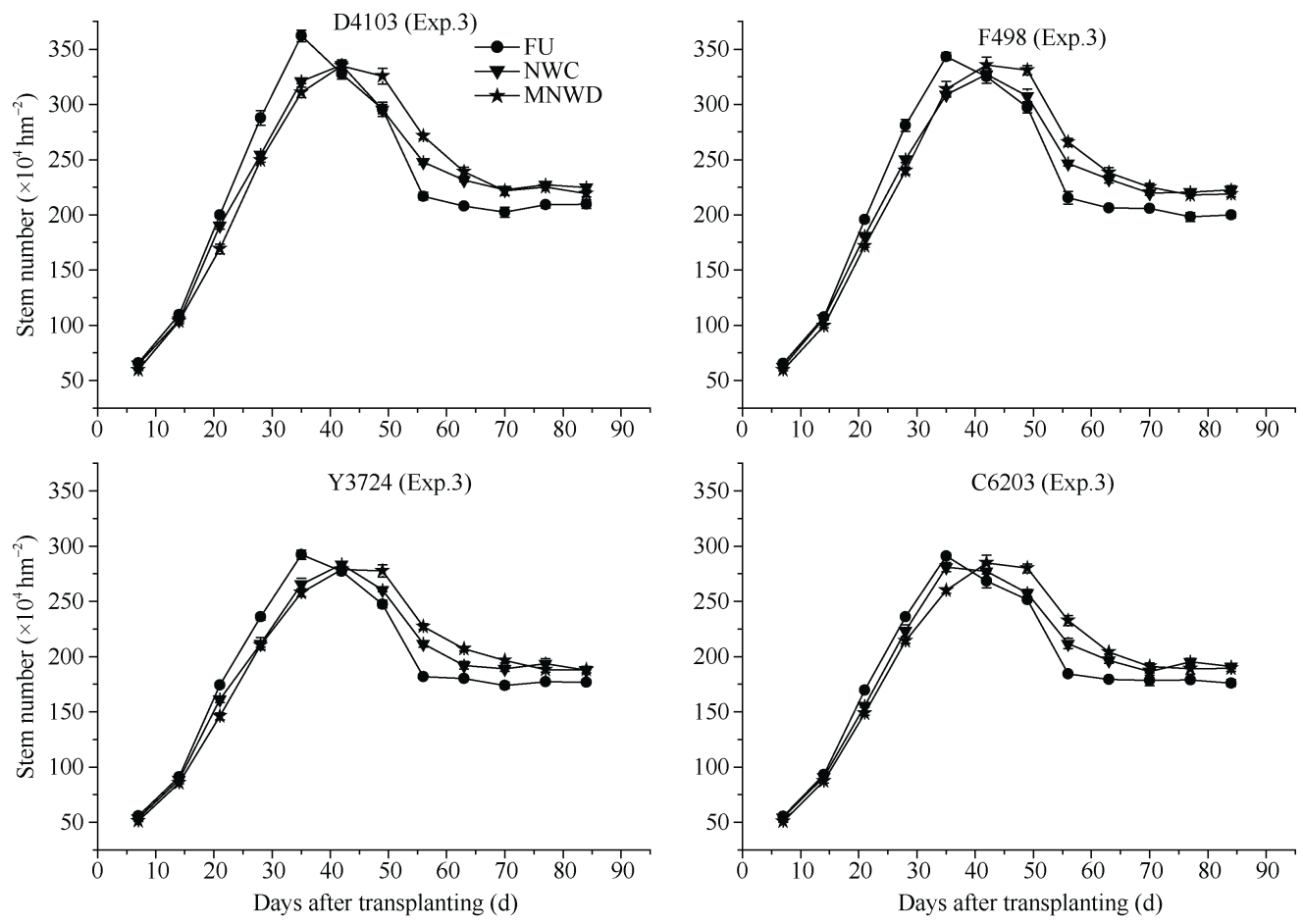

图 2 不同氮效率水稻差异型水氮管理条件下茎藍动态(涪城, 2017)

Fig. 2 Stem dynamics of hybrid rice with different $\mathrm{N}$ use efficiencies under varied nitrogen-water management modes (Fucheng, 2017)

F498: F 优 498; C6203: 川优 6203。缩写同表 4。

F498: Fyou 498; C6203: Chuanyou 6203. Abbreviations are the same as those given in Table 4.
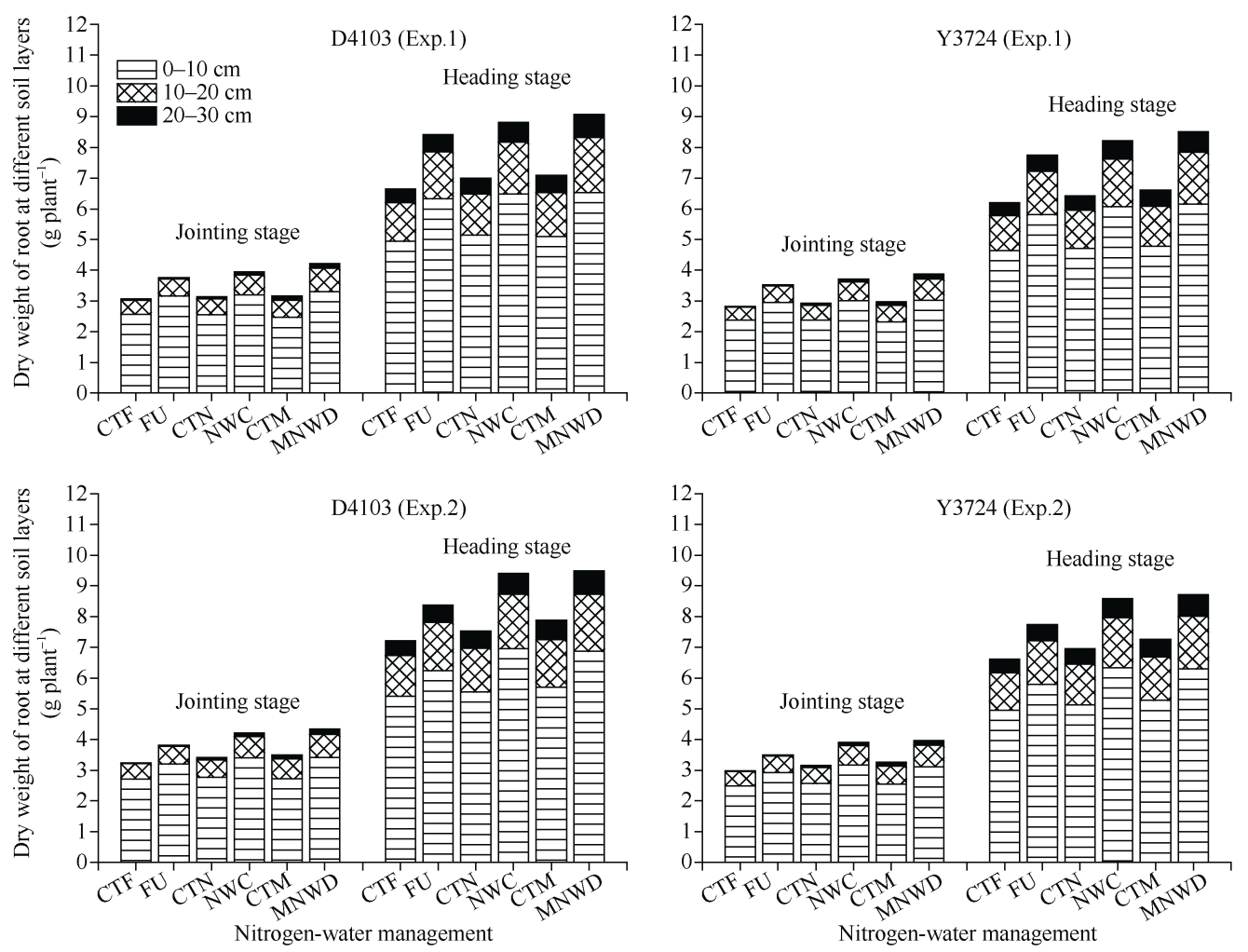

图 3 不同氮效率水稻差异型水氮管理条件下根系生长及分布(温江, 2015)

Fig. 3 Root growth and distribution of hybrid rice with different $\mathrm{N}$ use efficiencies under varied nitrogen-water management modes (Wenjiang, 2015)

缩写同表 4 和图 2。Abbreviations are the same as those given in Table 4 and Fig. 2. 

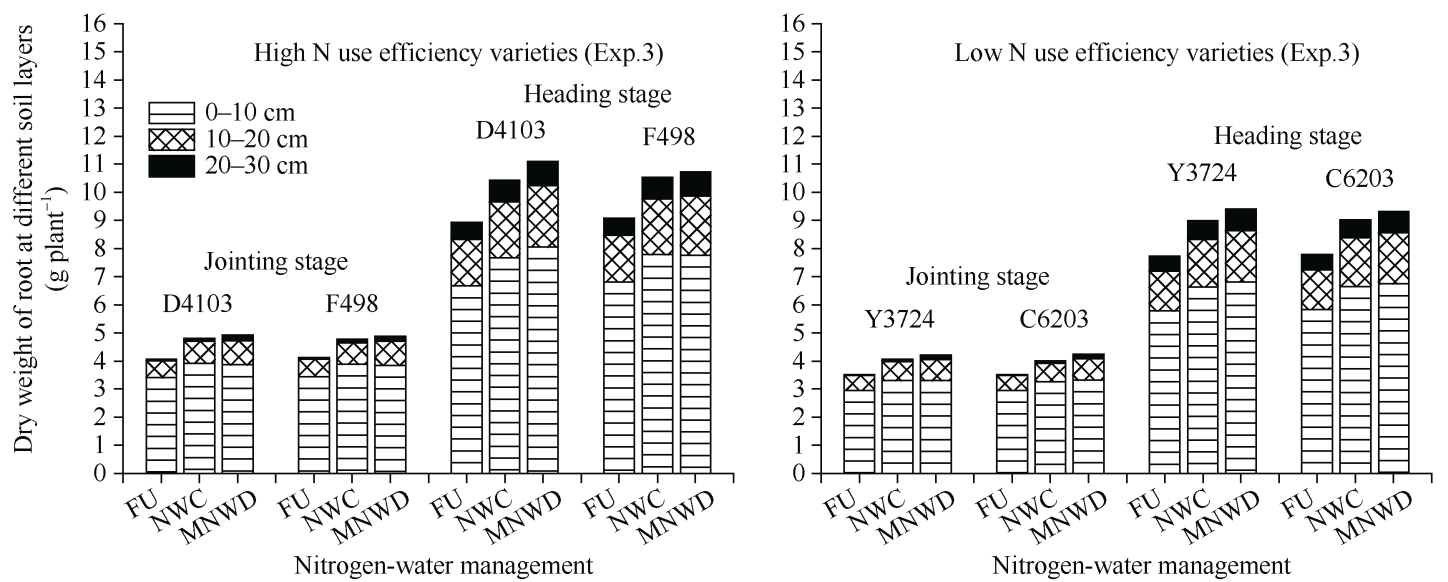

图 4 不同氮效率水稻差异型水氮管理条件下根系生长及分布(涪城, 2017)

Fig. 4 Root growth and distribution of hybrid rice with different $\mathrm{N}$ use efficiencies under varied nitrogen-water management modes (Fucheng, 2017)

缩写同表 4 和图 2。Abbreviations are the same as those given in Table 4 and Figure 2.

表 6 水氮管理对不同氮效率水稻氮素积累及氮肥利用的影响

Table 6 Effects of nitrogen-water management modes on $\mathrm{N}$ accumulation and $\mathrm{N}$ fertilizer utilization of hybrid rice with different $\mathrm{N}$ use efficiencies

\begin{tabular}{|c|c|c|c|c|c|c|c|c|}
\hline \multirow[b]{2}{*}{$\begin{array}{l}\text { 因素 } \\
\text { Factor }\end{array}$} & \multirow[b]{2}{*}{$\begin{array}{c}\text { 处理 } \\
\text { Treatment }\end{array}$} & \multicolumn{3}{|c|}{ 试验 1 Exp.1 } & \multicolumn{3}{|c|}{ 试验 2 Exp.2 } & \multirow{2}{*}{$\begin{array}{c}\text { 试验 } 3 \text { Exp.3 } \\
\text { 总吸氮量 } \\
\text { TNA } \\
\left(\mathrm{kg} \mathrm{hm}^{-2}\right)\end{array}$} \\
\hline & & $\begin{array}{c}\text { 总吸氮量 } \\
\text { TNA } \\
\left(\mathrm{kg} \mathrm{hm}^{-2}\right)\end{array}$ & $\begin{array}{c}\text { 氮肥回收 } \\
\text { 率 NRE } \\
(\%)\end{array}$ & $\begin{array}{c}\text { 氮肥农学利 } \\
\text { 用率 NAE } \\
\left(\mathrm{kg} \mathrm{kg}^{-1}\right)\end{array}$ & $\begin{array}{c}\text { 总吸氮量 } \\
\text { TNA } \\
\left(\mathrm{kg} \mathrm{hm}^{-2}\right)\end{array}$ & $\begin{array}{c}\text { 氮肥回收 } \\
\text { 率 NRE } \\
(\%)\end{array}$ & $\begin{array}{c}\text { 氮肥农学利 } \\
\text { 用率 NAE } \\
\left(\mathrm{kg} \mathrm{kg}^{-1}\right)\end{array}$ & \\
\hline \multirow{4}{*}{$\begin{array}{c}\text { 品种 } \\
\text { Cultivar (C) }\end{array}$} & D4103 & $150.65 \mathrm{a}$ & $51.56 \mathrm{a}$ & $19.07 \mathrm{a}$ & $171.06 \mathrm{a}$ & $48.60 \mathrm{a}$ & $17.40 \mathrm{a}$ & $202.35 \mathrm{a}$ \\
\hline & F498 & - & - & - & - & - & - & $200.31 \mathrm{a}$ \\
\hline & Y3724 & $140.71 \mathrm{~b}$ & $48.53 \mathrm{a}$ & $17.72 \mathrm{a}$ & $158.77 \mathrm{~b}$ & $42.94 \mathrm{a}$ & $15.87 \mathrm{a}$ & $173.82 \mathrm{~b}$ \\
\hline & C6203 & - & - & - & - & - & - & $173.11 \mathrm{~b}$ \\
\hline \multirow{6}{*}{$\begin{array}{c}\text { 氮肥管理 } \\
\text { Nitrogen } \\
\text { management } \\
\text { (N) }\end{array}$} & $\mathrm{CTF}$ & $108.42 \mathrm{~d}$ & - & - & $126.39 \mathrm{~d}$ & - & - & - \\
\hline & FU & $176.20 \mathrm{~b}$ & $45.18 \mathrm{~b}$ & $12.01 \mathrm{c}$ & $185.65 \mathrm{~b}$ & $39.51 \mathrm{c}$ & $10.76 \mathrm{c}$ & $175.50 \mathrm{c}$ \\
\hline & $\mathrm{CTN}$ & $110.59 \mathrm{~cd}$ & - & - & $135.39 \mathrm{~d}$ & - & - & - \\
\hline & NWC & $186.25 \mathrm{a}$ & $50.44 \mathrm{a}$ & $18.99 \mathrm{~b}$ & $204.64 \mathrm{a}$ & $46.14 \mathrm{~b}$ & $18.00 \mathrm{~b}$ & $196.73 \mathrm{a}$ \\
\hline & СТМ & $113.60 \mathrm{c}$ & - & - & $137.67 \mathrm{c}$ & - & - & - \\
\hline & MNWD & $179.01 \mathrm{~b}$ & $54.51 \mathrm{a}$ & $24.19 \mathrm{a}$ & 199.69 a & $51.67 \mathrm{a}$ & $21.14 \mathrm{a}$ & $189.96 \mathrm{~b}$ \\
\hline \multirow{3}{*}{$\begin{array}{c}F \text { 值 } \\
F \text {-value }\end{array}$} & $\mathrm{C}$ & $94.74^{* *}$ & $4.67^{\mathrm{NS}}$ & $3.94^{\mathrm{NS}}$ & $408.63^{* *}$ & $13.62^{\mathrm{NS}}$ & $0.68^{\mathrm{NS}}$ & $173.71^{* *}$ \\
\hline & $\mathrm{N}$ & $39.00^{* *}$ & $9.74^{* *}$ & $85.00^{* *}$ & $179.92^{* *}$ & $14.72^{* *}$ & $48.79^{* *}$ & $60.55^{* *}$ \\
\hline & $\mathrm{N}^{*} \mathrm{C}$ & $0.57^{\mathrm{NS}}$ & $0.08^{\mathrm{NS}}$ & $0.82^{\mathrm{NS}}$ & $0.79^{\mathrm{NS}}$ & $0.68^{\mathrm{NS}}$ & $0.30^{\mathrm{NS}}$ & $1.42^{\mathrm{NS}}$ \\
\hline
\end{tabular}

F498: F 优 498; C6203：川优 6203。TNA：总吸氮量; NAE：氮肥农学利用率; NRE：氮肥回收率。缩写同表 4。同一列数据后不同小写 字母表示不同品种间或不同施肥处理间在 0.05 水平差异显著。

F498: Fyou 498; C6203: Chuanyou 6203. TNA: total nitrogen accumulation; NAE: nitrogen agronomy efficiency; NRE: nitrogen recovery efficiency. Abbreviations are the same as those given in Table 4. Values within a column followed by different letters are significantly different at $P<0.05$ between cultivars or treatments. ${ }^{\text {NS }} P \geq 0.05 ;{ }^{* *} P<0.01 ;{ }^{*} P<0.05$.

2015 年试验，水稻移栽至收获期间降雨量为 $538.8 \mathrm{~mm}, 2017$ 年降水量为 $426.0 \mathrm{~mm}$ 。如图 5 所示, 由于水分管理一致，各水氮管理模式与各自对应的
空白对照灌水量几乎完全一致。采用“匀水”管理的 CTM 和 NMWD 灌水量最少, 平均约为 $3600 \mathrm{~m}^{3} \mathrm{hm}^{-2}$ (试验 1 和试验 2) 和 $4200 \mathrm{~m}^{3} \mathrm{hm}^{-2}$ (试验 3), 较采用 


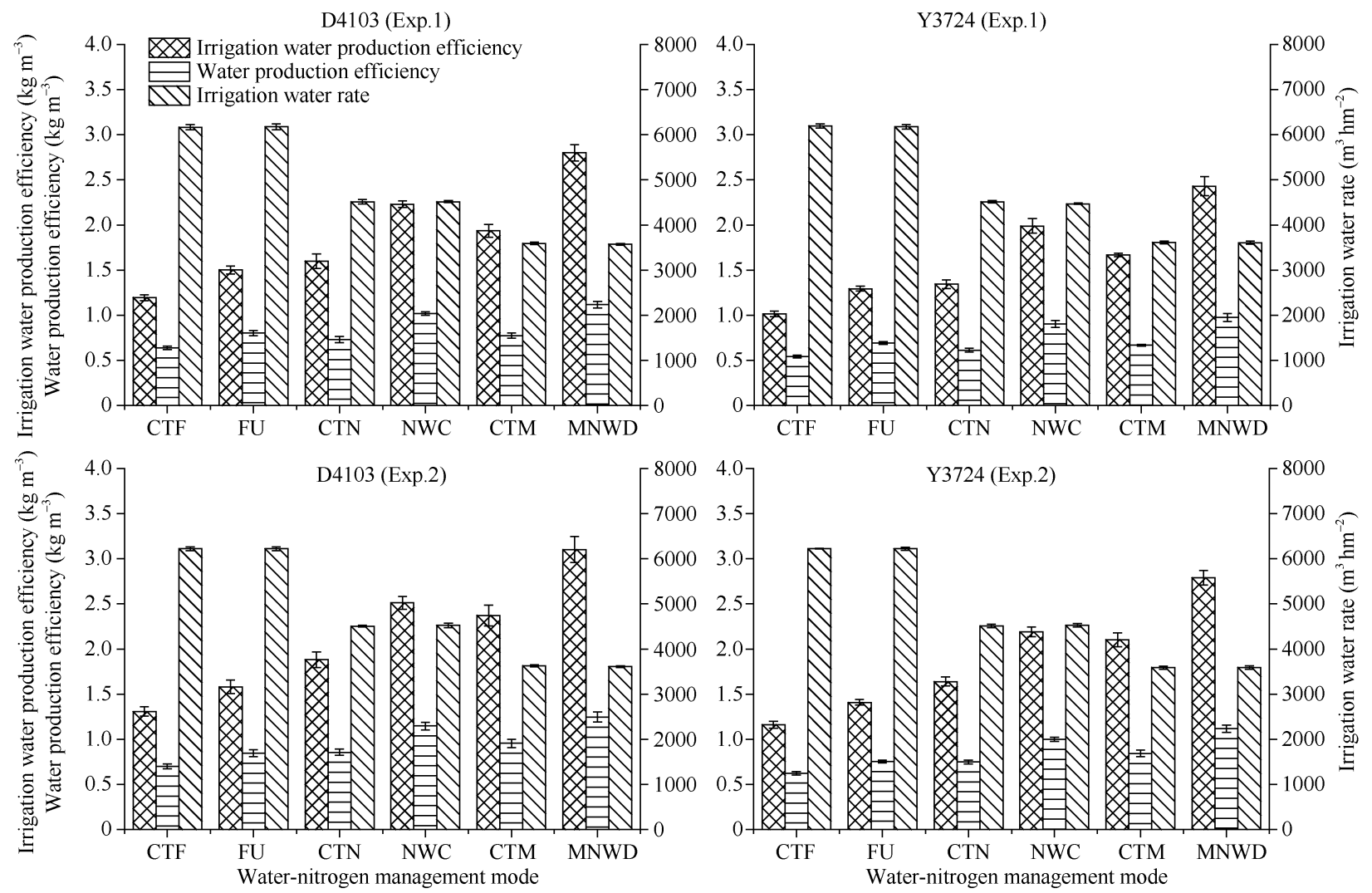

图 5 不同氮效率水稻差异型水氮管理条件下灌水量及水分利用(温江, 2015)

Fig. 5 Irrigation water rate and water use efficiency of hybrid rice with different $\mathrm{N}$ use efficiencies under varied nitrogen-water management modes (Wenjiang, 2015)

缩写同表 4 和图 2。Abbreviations are the same as those given in Table 4 and Fig. 2.

控制性灌溉的 CTN 和 NWC $\left(4500 \mathrm{~m}^{3} \mathrm{hm}^{-2}\right.$ 和 $5600 \mathrm{~m}^{3}$ $\mathrm{hm}^{-2}$ ) 节约 $20 \%$ 25\% 灌溉水, 较采用淹水灌溉的 CTF 和 FU (6200 $\mathrm{m}^{3} \mathrm{hm}^{-2}$ 和 $\left.8000 \mathrm{~m}^{3} \mathrm{hm}^{-2}\right)$ 减少 $42 \% \sim 48 \%$ 灌溉水，节水效果显著。

综合 3 个试验来看, 就灌溉水生产效率而言, 施氮条件下 $\mathrm{FU}$ 最低(1.00 1.66 $\left.\mathrm{kg} \mathrm{m}^{-3}\right), \mathrm{NWC}$ 居中 (1.62 2.57 $\left.\mathrm{kg} \mathrm{m}^{-3}\right)$, NMWD 最高(2.19 3.16 kg m $\mathrm{kg}^{-3}$ ), NMWD 的灌溉水生产效率较 FU 高出约 1 倍; 水分 生产效率规律与灌溉水生产效率基本一致。

2.5 水稻根系生长、分布与水、氮吸收利用的 关系

水稻根系生长、分布与水、氮吸收利用的相关 关系见表 7。低肥力条件下, 无论拔节期还是抽穗期, 各土层根干重与总吸氮量关系并不密切, 表层土壤 $(0 \sim 10 \mathrm{~cm})$ 根系亦对稻株氮肥和水分生产效率影响较 小。随着根系下扎，10 20 cm 土层根系与氮肥和水 分生产效率相关系数普遍达到显著水平, 到了
20 30 cm 土层, 根系与水、肥利用关系更加密切, 拔 节期 20 30 cm 土层根干重与水稻氮肥农学利用率 和灌溉水生产效率的相关系数甚至达到 0.96 。

与低肥力土壤不同, 高肥力土壤条件下, 各土 层根干重与总吸氮量关系密切, 且表层土壤根系对 氮肥和水分生产效率影响增强, 尤其与氮肥回收率 关系密切。到了抽穗期, $0 \sim 10 \mathrm{~cm}$ 土层根系已能够对 稻株灌溉水和水分生产效率发挥显著影响, 但与 $10 \mathrm{~cm}$ 以下土层根系相比, 影响程度仍存在差距, 越 是深层土壤根系越与稻株水、氮吸收利用关系密切, 这与低肥力土壤规律一致。

在温光条件优越, 但降水较少的涪城试验点, 根系与稻株氮素积累及水分高效利用关系更加密 切。各个土层根干重无一例外均与稻株氮素积累 和灌溉水生产效率及水分生产效率极显著正相关, 且越是深层次根系, 与植株水、氮吸收利用关系越 密切。 


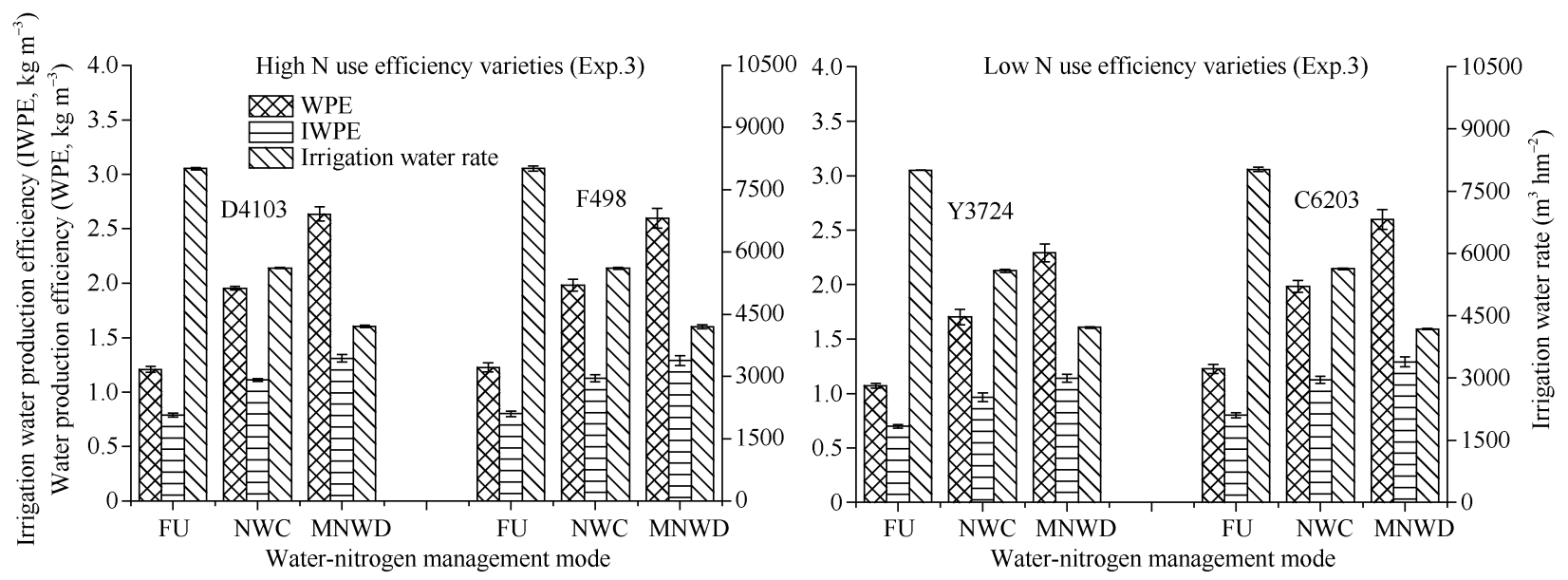

图 6 不同氮效率水稻差异型水氮管理条件下灌水量及水分利用(涪城, 2017)

Fig. 6 Irrigation water rate and water use efficiency of hybrid rice with different $\mathbf{N}$ use efficiencies under varied nitrogen-water management modes (Fucheng, 2017)

缩写同表 4 和图 2。Abbreviations are the same as those given in Table 4 and Fig. 2.

表 7 各土层根干重与氮素积累及水、氮利用的相关性

Table 7 Correlation of dry weight of root at different soillayers with $\mathrm{N}$ accumulation, water and $\mathrm{N}$ utilizations

\begin{tabular}{|c|c|c|c|c|c|c|c|}
\hline $\begin{array}{c}\text { 试验 } \\
\text { Experiment }\end{array}$ & $\begin{array}{l}\text { 时期 } \\
\text { Stage }\end{array}$ & $\begin{array}{c}\text { 土层深度 } \\
\text { DS }\end{array}$ & $\begin{array}{c}\text { 总吸氮量 } \\
\text { TNA }\end{array}$ & $\begin{array}{c}\text { 氮肥回收率 } \\
\text { NRE }\end{array}$ & $\begin{array}{c}\text { 氮肥农学利用率 } \\
\text { NAE }\end{array}$ & $\begin{array}{c}\text { 灌溉水生产效率 } \\
\text { IWPE }\end{array}$ & $\begin{array}{c}\text { 水分生产效率 } \\
\text { WPE }\end{array}$ \\
\hline 试验 1 & 拔节期 & $0-10 \mathrm{~cm}$ & $0.22^{\mathrm{NS}}$ & $0.33^{\mathrm{NS}}$ & $0.17^{\mathrm{NS}}$ & $0.28^{\mathrm{NS}}$ & $0.34^{\mathrm{NS}}$ \\
\hline \multirow[t]{7}{*}{ Exp.1 } & Jointing stage & $10-20 \mathrm{~cm}$ & $0.25^{\mathrm{NS}}$ & $0.77^{* *}$ & $0.84^{* *}$ & $0.85^{* *}$ & $0.81^{* *}$ \\
\hline & & $20-30 \mathrm{~cm}$ & $0.13^{\mathrm{NS}}$ & $0.79^{* *}$ & $0.96^{* *}$ & $0.96^{* *}$ & $0.88^{* *}$ \\
\hline & & $0-30 \mathrm{~cm}$ & $0.27^{\mathrm{NS}}$ & $0.62^{* *}$ & $0.54^{*}$ & $0.64^{* *}$ & $0.66^{* *}$ \\
\hline & 抽穗期 & $0-10 \mathrm{~cm}$ & $0.20^{\mathrm{NS}}$ & $0.27^{\mathrm{NS}}$ & $0.35^{\mathrm{NS}}$ & $0.39^{\mathrm{NS}}$ & $0.46^{\mathrm{NS}}$ \\
\hline & Heading stage & $10-20 \mathrm{~cm}$ & $0.30^{\mathrm{NS}}$ & $0.65^{* *}$ & $0.64^{* *}$ & $0.71^{* *}$ & $0.71^{* *}$ \\
\hline & & $20-30 \mathrm{~cm}$ & $0.24^{\mathrm{NS}}$ & $0.61^{* *}$ & $0.76^{* *}$ & $0.85^{* *}$ & $0.80^{* *}$ \\
\hline & & $0-30 \mathrm{~cm}$ & $0.29^{\mathrm{NS}}$ & $0.52^{*}$ & $0.61^{* *}$ & $0.68^{* *}$ & $0.72^{* *}$ \\
\hline 试验 2 & 拔节期 & $0-10 \mathrm{~cm}$ & $0.61^{* *}$ & $0.52^{*}$ & $0.45^{\mathrm{NS}}$ & $0.38^{\mathrm{NS}}$ & $0.45^{\mathrm{NS}}$ \\
\hline \multirow[t]{7}{*}{ Exp. 2} & Jointing stage & $10-20 \mathrm{~cm}$ & $0.70^{* *}$ & $0.78^{* *}$ & $0.86^{* *}$ & $0.91^{* *}$ & $0.92^{* *}$ \\
\hline & & $20-30 \mathrm{~cm}$ & $0.51^{*}$ & $0.82^{* *}$ & $0.86^{* *}$ & $0.97^{* *}$ & $0.91^{* *}$ \\
\hline & & $0-30 \mathrm{~cm}$ & $0.73^{* *}$ & $0.72^{* *}$ & $0.69^{* *}$ & $0.66^{* *}$ & $0.71^{* *}$ \\
\hline & 抽穗期 & $0-10 \mathrm{~cm}$ & $0.63^{* *}$ & $0.55^{*}$ & $0.39^{\mathrm{NS}}$ & $0.48^{*}$ & $0.54^{*}$ \\
\hline & Heading stage & $10-20 \mathrm{~cm}$ & $0.67^{* *}$ & $0.72^{* *}$ & $0.81^{* *}$ & $0.80^{* *}$ & $0.83^{* *}$ \\
\hline & & $20-30 \mathrm{~cm}$ & $0.51^{*}$ & $0.70^{* *}$ & $0.68^{* *}$ & $0.83^{* *}$ & $0.81^{* *}$ \\
\hline & & $0-30 \mathrm{~cm}$ & $0.71^{* *}$ & $0.67^{* *}$ & $0.57^{*}$ & $0.66^{* *}$ & $0.71^{* *}$ \\
\hline 试验 3 & 拔节期 & $0-10 \mathrm{~cm}$ & $0.80^{* *}$ & - & - & $0.54^{* *}$ & $0.62^{* *}$ \\
\hline \multirow[t]{7}{*}{ Exp.3 } & Jointing stage & $10-20 \mathrm{~cm}$ & $0.63^{* *}$ & - & - & $0.88^{* *}$ & $0.90^{* *}$ \\
\hline & & $20-30 \mathrm{~cm}$ & $0.42^{*}$ & - & - & $0.98^{* *}$ & $0.96^{* *}$ \\
\hline & & $0-30 \mathrm{~cm}$ & $0.81^{* *}$ & - & - & $0.73^{* *}$ & $0.79^{* *}$ \\
\hline & 抽穗期 & $0-10 \mathrm{~cm}$ & $0.72^{* *}$ & - & - & $0.63^{* *}$ & $0.69^{* *}$ \\
\hline & Heading stage & $10-20 \mathrm{~cm}$ & $0.71^{* *}$ & - & - & $0.81^{* *}$ & $0.85^{* *}$ \\
\hline & & $20-30 \mathrm{~cm}$ & $0.63^{* *}$ & - & - & $0.85^{* *}$ & $0.86^{* *}$ \\
\hline & & $0-30 \mathrm{~cm}$ & $0.75^{* *}$ & - & - & $0.73^{* *}$ & $0.78^{* *}$ \\
\hline
\end{tabular}

DS: 土层深度; TNA: 总吸氮量; NRE: 氮肥回收率; NAE: 氮肥农学利用率; IWPE: 灌溉水生产效率; WPE: 水分生产效率。

DS: depth of soillayers; TNA: total nitrogen accumulation; NRE: nitrogen recovery efficiency; NAE: nitrogen agronomy efficiency; IWPE: irrigation water production efficiency; WPE: water production efficiency. ${ }^{\mathrm{NS}} P \geq 0.05 ;{ }^{* *} P<0.01 ;{ }^{*} P<0.05$. 


\section{3 讨论}

\section{1 水肥“三匀”技术提高水稻产量}

目前研究普遍认为, 水稻高产群体必是花后高 光效群体, 水稻花后光合生产能力是影响水稻产量 的首要因素 ${ }^{[16-18]}$ 。在寡日高湿的四川盆地稻区, 水 稻花后群体荫闭、通风透光不佳的状况较常见, 导 致水稻群体花后光合产物积累较少, 不同产量水平 水稻群体间花后光合产物积累差异亦较小，花前物 质转运成为引起产量变化的决定性因素 ${ }^{[19]}$ 。在产量 较低的试验 1 中, D4103 依靠花前物质转运多和花后 光合生产旺的双重支撑保证了其对 Y3724 的产量优 势; 而在产量较高的试验 2 中, D4103 几乎仅凭借花 后光合生产优势就实现了对 Y 3724 的产量超越; 在 光温条件优越的试验 3 , 高产品种的产量优势大部 分依靠花后光合生产, 少部分通过更多花前物质转 运实现。试验 1 和试验 2 比较而言, 在光温资源较 差的稻区, 要打破水稻产量潜力天花板, 实现水稻 产量进一步增长, 获取更多的花后光合产物是重中 之重。综合试验 2 和试验 3 来说, 光温资源较差地 区水稻生产亦能如光温资源优越地区一样, 通过塑 造花后光合生产能力强的高质量水稻群体来寻求产 量突破，在这个过程中，针对性地配套栽培措施， 更好地发挥高产品种花后干物质积累多的优势, 更 高水平地激发良种良法的协同效应是核心步骤。

与高产品种产量优势发挥尚需花前物质转运多 这一条件支撑不同，不同水氮管理模式间产量的差 异则由花后光合生产主导。即较优的水氮管理模式 塑造的高质量水稻群体, 花前物质转运量较少, 但 其花后光合生产性能强劲; 在补偿了花前物质转运 的亏缺后, 剩余部分仍能持平或领先采用了其他水 氮管理模式的水稻群体的花后光合产物积累; 持平 者如 MNWD 与 NWC, 领先者如 MNWD 与 FU, 这 表明花后光合生产能力强是 MNWD 较突出的特点。 在奠定中国现代水稻栽培基础的水稻群体质量理论 中, 成穗率是最核心的群体质量指标, 适宜穗数基 础上的高成穗率水稻群体必是高产群体 ${ }^{[20-21]}$ 。减氮 $20 \%$ 的 MNWD 水稻群体茎藍数量缓升缓降, 高峰苗 数量少, 但成穗数量多, 成穗率与 NWC 相近, 较 $\mathrm{FU}$ 有较大优势。已有研究普遍认为高产水稻群体高 峰苗宜出现在拔节期 ${ }^{[22-23]}$, 对四川盆地稻区而言, 高峰苗出现时间尤其关键, 高峰苗若出现过早需提 前且深度晒田控藍, 这对寡日高湿的盆地气候而言
较难实现, 导致孕穗期水稻群体包含较多无效分薛, 有效分藍穗分化所需营养因竞争加剧而得不到保证, 大穗难以形成; 高峰苗若出现过迟，拔节后稻株养 分供给向穗分化倾斜，后发分蔾因营养供给不足难 以成穗，导致群体有效穗数不足。四川盆地由于寡 照高湿的气候特点, 水稻高产一直围绕攻取大穗展 开, 有效穗数较其余稻区有较大差距, 在此情况下, 有效穗数减少无疑会带来更大的产量损失。MNWD 与 NWC 高峰苗出现时间均为移栽后 $42 \mathrm{~d}$ 左右, 与 拔节期基本重合，且成穗率较高，符合高产群体要 求, 最终均获得较高产量。比较而言, MNWD 氮肥 投入更少且花后光合生产性能占据较大优势，从养 分高效利用及技术通用性而言更具优势。

\section{2 水肥“三匀”技术提高水稻水氮利用效率}

土壤适度干旱有利于作物根系下扎汲取营养和 水分, 长期淹水稻株根系活力弱, 对水、肥吸收能力 差, 限制水稻产量和养分利用效率提高，干湿交替 灌溉被认为是较合理的稻田水分管理方式 ${ }^{[24-26]}$ 。就 目前常见的干湿交替灌溉结合基、菜、穗氮撒施的 水氮耦合模式而言，水氮耦合的紧密程度受到较大 局限，原因在于灌水后撒施的氮肥更多地存在于表 层土壤, 下部耕层获得氮肥较少, 导致这部分土壤 水分的变化对氮肥的影响有限。水、氮一体化可实 现氮随水走, 解决水氮脱节的难题, 也意味着耕层 水分较细微的变化也可能对水氮耦合效果产生较大 影响。当土壤适度干旱时, 水、氮一体化施用, 能加 速氮肥溶解, 促进氮肥向稻株根部移动, 提高氮肥 利用率; 当土壤过度干旱时, 水、氮一体化施用, 氮 肥易随灌溉水渗漏至下部非耕层土壤而损失, 导致 水、氮利用效率同时降低; 当土壤干后灌水未至饱 和状态时，氮肥会随水更多进入耕层下部土壤，导 致供应数量最为庞大的上层土壤根系的水、氮不足, 于水稻群体生长发育不利; 当土壤干后灌水过量时, 稻田长时间处于淹水状态，不但不利于稻株根系活 力保持, 还会加速干旱过程中形成的硝态氮的反硝 化过程, 加剧氮肥损失 ${ }^{[27-28]}$ 。故水氮一体化模式下 干湿转换临界值的确定需统筹考虑水分和氮肥投入 的数量、时间及相互比例的协调关系，以最大化彰 显水氮耦合的协同而非拮抗效应。水肥“三匀”技术 通过减基、控菜、调穗和增粒肥的思路将氮肥投入 时间由 $2 \sim 4$ 次扩展为 7 8 次, 单次氮肥施用量由 $30 \sim 105 \mathrm{~kg} \mathrm{hm}^{-2}$ 降至 $15 \sim 30 \mathrm{~kg} \mathrm{hm}^{-2}$, 实现氮肥投入 频率和施用量的逐步均匀化，较氮肥集中大量投入 
的农民模式和干湿交替结合基、葟、穗肥撒施的水 氮耦合模式提高了回收率。水肥“三匀”技术采用的 匀水管理模式不建立可见水层, 减少了田面水蒸发, 节约了灌溉用水。水肥“三匀”技术于地下 $30 \mathrm{~cm}$ 土 壤水势约为 $0 \mathrm{kPa}$ 时灌溉至土壤饱和为止, 水氮同 步在耕层土壤中趋于均匀分布, 与表层撒肥相比, 水氮空间均匀的特点改善了下部耕层的氮素环境, 有效引导了稻株根系下扎汲取水分和营养, 提高了 水稻群体的水、氮利用效率。从各土层根系与水稻 水氮利用效率的关系看，水肥“三匀”技术下部土层 根系发达的特点极可能是其水、氮利用优势的关键 所在。

水肥“三匀”技术较多的施肥、灌水次数无疑会 提高劳动力成本投入，削弱其实际价值。对此，可利 用水肥一体化设备 (以水压差、燃油或电力为动力) 将肥料与灌溉水混合均匀, 灌水施肥同步完成, 操 作简单，有利于该技术的推广应用。

\section{4 结论}

水肥“三匀”技术依靠频度均匀、数量均匀和空 间分布均匀实现水稻生产中的匀水匀肥管理, 较干 湿交替灌溉结合基、菜、穗肥撒施的水氮耦合管理 减少 $20 \%$ 氮肥投入的同时，产量保持稳定，较农民 习惯模式平均增产 $8.77 \%$ 14.18\%。采用水肥“三匀” 技术稻株根量大, 分布于下部土层的根系发达, 提 高了水稻水、氮利用效率。与农民习惯模式相比，水 肥“三匀”技术氮肥回收率平均提高 $20.72 \%$ 30.78\%, 农学利用率平均提高 $96.47 \% \sim 101.42 \%$, 灌溉水生产 效率平均提高 $76.54 \%$ 117.38\%。

\section{References}

[1] Deng N Y, Grassini P, Yang H S, Huang J L, Cassman K G, Peng S B. Closing yield gaps for rice self-sufficiency in China. Nat Commun, 2019, 10: 1725.

[2] 凌启鸿, 张洪程, 蔡建中, 苏祖芳, 凌励. 水稻高产群体质量 及其优化控制探讨. 中国农业科学, 1993, 26(6): 1-11.

Ling Q H, Zhang H C, Cai J Z, Su Z F, Ling L. Investigation on the population quality of high yield and its optimizing control programme in rice. Sci Agric Sin, 1993, 26(6): 1-11 (in Chinese with English abstract).

[3] 刍应斌, 黄见良, 屠乃美, 李合松, 黄升平, 张杨珠. “旺壮重” 栽培对双季杂交稻产量形成及生理特性的影响. 作物学报, 2001, 27: 343-350.

Zou Y B, Huang J L, Tu N M, Li H S, Huang S P, Zhang Y Z. Effects of the VSW cultural method on yield formation and physiological characteristics in double cropping hybrid rice. Acta Agron Sin, 2001, 27: 343-350 (in Chinese with English abstract).

[4] 蒋鹏, 黄敏, Md. Ibrahim, 曾燕, 夏冰, 施婉菊, 谢小兵, 刍应 斌. “三定”栽培对双季超级稻养分吸收积累及氮肥利用率的影 响. 作物学报, 2011, 37: 2194-2207.

Jiang P, Huang M, Ibrahim M, Zeng Y, Xia B, Shi W J, Xie X B, Zou Y B. Effects of "sanding" cultivation method on nutrient uptake and nitrogen use efficiency in double cropping super rice. Acta Agron Sin, 2011, 37: 2194-2207 (in Chinese with English abstract).

[5] 张洪程, 郭保卫, 陈厚存, 周兴涛, 张军, 朱聪聪, 陈京都, 李 桂云, 吴中华, 戴其根, 霍中洋, 许轫, 魏海燕, 高辉, 杨雄. 水稻有序摆、抛栽的生理生态特征及超高产形成机制. 中国农 业科学, 2013, 46: 463-475.

Zhang H C, Guo B W, Chen H C, Zhou X T, Zhang J, Zhu C C, Chen J D, Li G Y, Wu Z H, Dai Q G, Huo Z Y, Xu K, Wei H Y, Gao H, Yang X. Eco-physiological characteristics and super high yield formation mechanism of ordered transplanting and optimized broadcasting rice. Sci Agric Sin, 2011, 37: 2194-2207 (in Chinese with English abstract).

[6] 汪仁全, 马均, 童平, 张荣萍, 李艳, 傅泰露, 吴合洲, 刘志彬. 三角形强化栽培技术对水稻光合生理特性及产量形成的影响. 杂交水稻, 2006, 21(6): 60-65.

Wang R Q, Ma J, Tong P, Zhang R P, Li Y, Fu T L, Wu H Z, Liu $Z$ B. Effects of planting method of triangle of system of rice intensification (TSRI) on photosynthetic characteristics and formation of grain yield. Hybrid Rice, 2006, 21(6): 60-65 (in Chinese with English abstract).

[7] 薛超, 周宏. 污染排放约束下中国水稻生产用水效率与影响 因素分析. 水资源保护, 2018, 34(3): 52-56.

Xue C, Zhou H. Analysis on rice production water use efficiency and its influencing factors in China under constraint of pollutant emission. Water Resour Prot, 2018, 34(3): 52-56 (in Chinese with English abstract).

[8] 王杰飞, 朱潚, 沈健林, 曾冠军, 王娟, 吴金水, 李勇. 亚热带 稻区大气氨/铵态氮污染特征及干湿沉降. 环境科学, 2017, 38: 2264-2272.

Wang J F, Zhu X, Shen J L, Zeng G J, Wang J, Wu J S, Li Y. Atmospheric ammonia/ammonium-nitrogen concentrations and wet and dry deposition rates in a double rice region in subtropical China. Environ Sci, 2017, 38: 2264-2272 (in Chinese with English abstract).

[9] Wang J, Fu P, Wang F, Fahad, S, Mohapatra P K, Chen Y T, Zhang C D, Peng S B, Cui K H, Nie L X, Huang J L. Optimizing nitrogen management to balance rice yield and environmental risk in the Yangtze River's middle reaches. Environ Sci Pollut Res, 2019, 26: 4901-4912.

[10] 孙永健, 孙园园, 徐徽, 李玥, 严奉君, 蒋明金, 马均. 水氮管 理模式对不同氮效率水稻氮素利用特性及产量的影响. 作物 学报, 2014, 40: 1639-1649.

Sun Y J, Sun Y Y, Xu H, Li Y, Yan F J, Jiang M J, Ma J. Effects 
of water-nitrogen management patterns on nitrogen utilization characteristics and yield in rice cultivars with different nitrogen use efficiencies. Acta Agron Sin, 2014, 40: 1639-1649 (in Chinese with English abstract).

[11] 彭玉, 孙永健, 蒋明金, 徐徽, 秦俭, 杨志远, 马均. 不同水分 条件下缓/控释氮肥对水稻干物质量和氮素吸收、运转及分配 的影响. 作物学报, 2014, 40: 859-870.

Peng Y, Sun Y J, Jiang M J, Xu H, Qin J, Yang Z Y, Ma J. Effects of water management and slow/controlled release nitrogen fertilizer on biomass and nitrogen accumulation, translocation, and distribution in rice. Acta Agron Sin, 2014, 40: 859-870 (in Chinese with English abstract).

[12] 李娜, 杨志远, 代邹, 孙永健, 徐徽, 何艳, 蒋明金, 严田蓉, 郭长春, 马均. 水氮管理对不同氮效率水稻根系性状、氮素吸 收利用及产量的影响. 中国水稻科学, 2017, 31: 500-512.

Li N, Yang Z Y, Dai Z, Sun Y J, Xu H, He Y, Jiang M J, Yan T R, Guo C C, Ma J. Effects of water-nitrogen management on root traits, nitrogen accumulation and utilization and grain yield in rice with different nitrogen use efficiency. Chin J Rice Sci, 2017, 31: 500-512 (in Chinese with English abstract).

[13] Huang J, He F, Cui K, Buresh R J, Xu B, Gong W H, Peng S B. Determination of optimal nitrogen rate for rice varieties using a chlorophyll meter. Field Crops Res, 2008, 105: 70-80.

[14] Xiong D L, Chen J, Yu T T, Gao W L, Ling X X, Li Y, Peng S B, Huang J L. SPAD-based leaf nitrogen estimation is impacted by environmental factors and crop leaf characteristics. Sci Rep, 2015, 5: 13389.

[15] Miao Y, Stewart B A, Zhang F. Long-term experiments for sustainable nutrient management in China: a review. Agron Sustain Dev, 2011, 31: 397-414.

[16] Huang L Y, Yang D S, Li X X, Peng S B, Wang F. Coordination of high grain yield and high nitrogen use efficiency through large sink size and high post-heading source capacity in rice. Field Crops Res, 2019, 233: 49-58.

[17] 韦还和, 孟天瑶, 李超, 张洪程, 史天宇, 马荣荣, 王晓燕, 杨 筠文, 戴其根, 霍中洋, 许轲, 魏海燕, 郭保卫. 甬优籼粳杂 交稻花后干物质积累模型与特征分析. 作物学报, 2016, 42: 265-277.

Wei H H, Meng T Y, Li C, Zhang H C Shi T Y, Ma R R, Wang X Y, Yang J W, Dai Q G, Huo Z Y, X K, Wei H Y, Guo B W. Dynamic model and its characteristics analysis for dry matter production after heading of indica/japonica hybrid rice of Yongyou series. Acta Agron Sin, 2016, 42: 265-277 (in Chinese with English abstract).

[18] 许轫, 郭保卫, 张洪程, 周兴涛, 陈厚存, 张军, 陈京都, 朱聪 聪, 李桂云, 吴中华, 戴其根, 霍中洋, 魏海燕, 高辉, 曹利强, 李明银. 有序摆抛栽对超级稻超高产与光合生产力的影响及 水稻超高产模式探索. 作物学报, 2013, 39: 1652-1667.

Xu K, Guo B W, Zhang H C, Zhou X T, Chen H C, Zhang J, Chen J D, Zhu C C, Li G Y, Wu Z H, Dai Q G, Huo Z Y, Wei H Y, Gao H, Cao L Q, Li M Y. Effect of ordered transplanting and optimized broadcasting on super high yield and photosynthetic productivity and exploration of rice super high yield model. Acta Agron Sin, 2013, 39: 1652-1667 (in Chinese with English abstract).

[19] 杨志远, 胡蓉, 孙永健, 徐徽, 许远明, 马均. 三角形强化栽 培模式下氮肥运筹对 II 优 498 产量及氮肥利用的影响. 作物学 报, 2012, 38: 1097-1106.

Yang Z Y, Hu R, Sun Y J, Xu H, Xu Y M, Ma J. Effects of nitrogen fertilizer management on yield and nitrogen use efficiency of Eryou 498 in triangle-planted system of rice intensification. Acta Agron Sin, 2012, 38: 1097-1106 (in Chinese with English abstract).

[20] 凌启鸿, 苏祖芳, 张海泉. 水稻成穗率与群体质量的关系及其 影响因素的研究. 作物学报, 1995, 21: 463-469.

Ling Q H, Su Z F, Zhang H Q. Relationship between earbearing tiller percentage and population quality and its influential factors in rice. Acta Agron Sin, 1995, 21: 463-469 (in Chinese with English abstract).

[21] 蒋彭炎, 洪晓富, 冯来定, 马跃芳, 史济林, 倪竹如, 刘智宏. 水稻中期群体成穗率与后期群体光合效率的关系. 中国农业 科学, 1994, 27(6): 8-14.

Jiang P Y, Hong X F, Feng D L, Ma Y F, Shi J L, Ni Z R, Liu Z H. Relation between percentage of ear-bearing of colony in the middle phase and photosynthesis efficiency in the late in rice. Sci Agric Sin, 1994, 27(6): 8-14 (in Chinese with English abstract).

[22] 王晓燕, 韦还和, 张洪程, 孙健, 张建民, 李超, 陆惠斌, 杨筠 文, 马荣荣, 许久夫, 王玨, 许跃进, 孙玉海. 水稻角优 12 产 量 $13.5 \mathrm{t} \mathrm{hm}^{-2}$ 以上超高产群体的生育特征. 作物学报, 2014, 40: 2149-2159.

Wang X Y, Wei H H, Zhang H C, Sun J, Zhang J M, Li C, Lu H B, Yang J W, Ma R R, Xu J F, Wang J, Xu Y J, Sun Y H. Population characteristics for super-high yielding hybrid rice Yongyou 12 ( >13.5 $\mathrm{t} \mathrm{ha}^{-1}$ ). Acta Agron Sin, 2014, 40: 2149-2159 (in Chinese with English abstract).

[23] 张洪程, 吴桂成, 李德剑, 肖跃成, 龚金龙, 李杰, 戴其根, 霍 中洋, 许轫, 高辉, 魏海燕, 沙安勤, 周有炎, 王宝金, 吴爱国. 杂交粳稻 $13.5 \mathrm{t} \mathrm{hm}^{-2}$ 超高产群体动态特征及形成机制的探讨. 作物学报, 2010, 36: 1547-1558.

Zhang H C Wu G C, Li D J, Xiao Y C, Gong J L, Li J, Dai Q G, Huo Z Y, Xu K, Gao H, Wei H Y, Sha A Q, Zhou Y Y, Wang B J, Wu A G. Population characteristeristics and formation mechanism for super-high-yielding hybrid japonica rice (13.5 $\left.\mathrm{t} \mathrm{ha}^{-1}\right)$. Acta Agron Sin, 2010, 36: 1547-1558 (in Chinese with English abstract).

[24] 徐云姬, 许阳东, 李银银, 钱希旸, 王志琴, 杨建昌. 干湿交 替灌溉对水稻花后同化物转运和籽粒灌浆的影响. 作物学报, 2018, 44: 554-568.

Xu Y J, Xu Y D, Li Y Y, Qian X Y, Wang Z Q, Yang J C. Effect of alternate wetting and drying irrigation on post-anthesis remobilization of assimilates and grain filling of rice. Acta Agron Sin, 2018, 44: 554-568 (in Chinese with English abstract). 
[25] 徐国伟, 陆大克, 孙会忠, 王贺正, 李友军. 干湿交替灌溉与 施氮耦合对水稻根际环境的影响. 农业工程学报, 2017, 33: 186-194.

Xu G W, Lu D K, Sun H Z Wang H Z, Li Y J. Effect of alternative wetting and drying irrigation and nitrogen coupling on rhizosphere environment of rice. Trans CSAE, 2017, 33: 186-194 (in Chinese with English abstract).

[26] 褚光, 展明飞, 朱宽宇, 王志琴, 杨建昌. 干湿交替灌溉对水 稻产量与水分利用效率的影响. 作物学报, 2016, 42: 1026-1036.

Chu G, Zhan M F, Zhu K Y, Wang Z Q, Yang J C. Effects of alternate wetting and drying irrigation on yield and water use efficiency of rice. Acta Agron Sin, 2016, 42: 1026-1036 (in
Chinese with English abstract).

[27] 曹娜, 王睿, 廖婷婷, 陈诺, 郑循华, 姚志生, 张海, Klaus B B. 厌氧条件下砂壤水稻土 $\mathrm{N}_{2} 、 \mathrm{~N}_{2} \mathrm{O} 、 \mathrm{NO} 、 \mathrm{CO}_{2}$ 和 $\mathrm{CH}_{4}$ 排放特征. 环境科学, 2015, 36: 3373-3382.

Cao N, Wang R, Liao T T, Chen N, Zheng X H, Yao Z S, Zhang $\mathrm{H}$, Klaus B B. Characteristics of $\mathrm{N}_{2}, \mathrm{~N}_{2} \mathrm{O}, \mathrm{NO}, \mathrm{CO}_{2}$ and $\mathrm{CH}_{4}$ emissions in anaerobic condition from sandy loam paddy soil. Environ Sci, 2015, 36: 3373-3382 (in Chinese with English abstract).

[28] Tan X Z, Shao D G, Gu W Q. Effects of temperature and soil moisture on gross nitrification and denitrification rates of a Chinese lowland paddy field soil. Paddy Water Environ, 2018, 16: 687-698. 